\title{
THE TRANSMISSION MECHANISM OF EUROPEAN MONETARY POLICY: IS THERE HETEROGENEITY? IS IT CHANGING OVER TIME?
}

Matteo Ciccarelli and Alessandro Rebucci 


\title{
THE TRANSMISSION MECHANISM OF EUROPEAN MONETARY POLICY: IS THERE HETEROGENEITY? \\ IS IT CHANGING OVER TIME? (*)
}

\author{
Matteo Ciccarelli \\ UNIVERSIDAD DE ALICANTE \\ Alessandro Rebucci \\ INTERNATIONAL MONETARY FUND
}

(*) We are particularly grateful to Fabio Canova for extensive comments on a previous draft of the paper and very useful discussions. We are thankful also to Luigi Guiso and Fernando Restoy for their suggestions and encouragement, and to Juan Dolado, Jordi Galí, Chris Gilbert, Ron Smith, Elias Tzavalis, Javier Vallés and the participants to seminars at Banco de España, Boston College, CEMFI, ECB, "Ente Einaudi", IMF, and the V International Conference on Macroeconomic Analysis and International Finance for comments and discussions. We thank Marcello Pericoli at the Bank of Italy for providing us daily exchange rates data. Ciccarelli's research was undertaken while he was a research fellow at the Bank of Spain. The views expressed in this paper are exclusively those of the authors and not those of the International Monetary Fund. The usual disclaimer applies. E-mails: matteo@merlin.fae.ua.es; arebucci@imf.org. 



\section{Introduction}

The European Central Bank (ECB) has already moved interest rates several times since it started to operate in January 1999 and yet we don't know what the magnitude and timing of the effects of its actions actually are. What are the effects on prices and output of a change in the common short-term interest rate? How long do these effects take to materialize? Are there differences in the impact across European countries and regions? Are these differences changing over time? Most of these questions have already been asked in the literature. However, the answers provided so far are not entirely satisfactory.

Monticelli and Tristani (1999), for instance, suggest to start considering the European Monetary Union (EMU) as a composite economic system rather than a collection of countries. They analyze the impact of monetary policy on what is called the 'EMU-wide economic system' by estimating a structural VAR with a GDP-based weighted average of individual time series of member countries. ${ }^{1}$ If the transmission mechanism is similar across European countries, this approach provides a measure of the European-wide effects of monetary policy which is as good as those obtained with alternative estimation methods. But if the transmission mechanism does differ across countries, i.e., if there are cross country differences in the effects of monetary policy, this approach is not correct. In this case, as shown by Pesaran and Smith (1995) for standard dynamic panel data models and discussed by Rebucci (2000) for panel VAR specifications, aggregation of individual time series may bias the estimates obtained, and the European-wide impact of monetary policy must be measured either aggregating individual time series estimates or using other methods that allow for explicit variation of the parameters across countries. Before attempting to measure the system-wide effects of a 'synthetic' common monetary policy, therefore, one should try to establish whether or not there are differences across countries in the transmission mechanism of monetary policy.

The current consensus view is that, indeed, there are differences across European coun-

\footnotetext{
${ }^{1}$ A similar approach is followed by Peersman and Smets (2001) in studying whether monetary policy has asymmetric effects across business cycle states in European countries, and by Ortega and Alberola (2000) in analyzing the impact on the Euro-area of different kinds of shocks.
} 
tries in the transmission mechanism of monetary policy. Differences that are likely to decrease over time as real, and especially financial, convergence proceeds.

The existence of some degree of heterogeneity in the transmission mechanism of European monetary policy is supported by a large, albeit sometimes contradicting, body of empirical evidence. ${ }^{2}$ Gerlach and Smets (1995), for example, find very different results depending on the type of experiment they run. In their study, the effects on GDP of a one period, one standard deviation shock to short-term interest rates are broadly similar across Germany, France, and Italy. However, when they simulate a 100 basis points increase in interest rates sustained for two-years, they find that German GDP falls almost twice as much as that of France and Italy. On the other hand, Ramaswamy and Sloek (1997) find that the effects on GDP of a one period, one standard deviation shock to short-term interest rates in Germany, the U. K., Finland, the Netherlands, Austria, and Belgium take almost twice as long to occur, but are almost twice as deep as in Denmark, France, Italy, Portugal, Spain and Sweden. Furthermore, Dornbusch, Favero, and Giavazzi (1998) find evidence suggesting that the long run effects on output growth of the predicted component of monetary policy in Germany, France, Italy, Spain, the U.K., and Sweden are quantitatively sizable and heterogeneous, while the impact effects are relatively more homogenous across these countries. Indeed, standard macroeconomic theory predicts that monetary policy is neutral in the long run, and hence its effects should be rather homogenous across countries over this time horizon, while they could be very different in the short run. As noted by Dornbusch and others (1998), there is also a difference between the results based on large econometric models and those based on small econometric models, whereas small (VAR-type) econometric models do not seem to be able to detect statistically significant cross-country differences in the monetary transmission mechanism, contrary to the evidence coming from large country-specific econometric models.

There are several methodological reasons why different studies might have come to very different conclusions. As noted by Guiso and others (2000), the specification of the econometric model sometime differs across countries. It is difficult therefore to establish the extent to which different outcomes reflect true differences in transmission mechanism of monetary

\footnotetext{
${ }^{2}$ See Guiso and others, 2000, among others, for a survey of this literature.
} 
policy or more simply different econometric specifications. Second, most studies compare the economy's response to identified monetary policy shocks neglecting completely interdependence between countries. This can obviously provides only a partial description of the transmission mechanism of monetary policy in open economies of a relatively well integrated region. In addition, it may seriously distort the identification of country speciflc monetary policy shocks. As noted by Dornbusch and others (1998), omitting the contemporaneous effect of German interest rates in the reaction function of other European central banks may erroneously lead to identify as local monetary shock what in fact is an endogenous response to a German monetary shock. Third, as noted again by Guiso and others (2000), the kind of experiment usually run is not informative on what is likely to happen under EMU: only some of these studies control for intra-Europe exchange rate movements which have disappeared under EMU, very few control for heterogeneous preferences over inflation and output stabilization objectives in central banks' preferences also disappeared under EMU, and basically none does both these two things at the same time. All this literature, finally, is potentially subject to the Lucas' critique as it attempts to draw inference relevant for EMU based on econometric models estimated under a different regime---the fixed, but adjustable, exchange rate regime (ERM) of the European Monetary System (EMS) in place until December 1998.

At the same time, there is no hard evidence that these differences are decreasing over time. On the contrary, recent work by Cecchetti (1999) shows that they might persist for a long time because they are due to differences in the financial structure, which in turn are rooted in the legal framework of individual countries. If these differences were to persist for sometime, the ECB's life may become quite complicated as pointed out by Dornbusch and others (1998), explicitly modelled by Giovannetti and Marimon (1998), and analyzed empirically by Hughes-Hallet and Piscitelli (1998 and 1999), among others. Therefore, it would be useful to have some idea not only on the magnitude of these differences, but also on their degree of persistence over time.

We propose to overcome some of these difficulties by rephrasing some of the questions above in the framework of a dynamic heterogenous panel data model recently proposed by Canova and Ciccarelli (2000). This is a flexible empirical framework where, in addition 
to interdependencies among individual units, the parameter of the transmission mechanism can change both across times and individual units. This framework therefore allows for the maximum degree of heterogeneity across countries and over time, and sets the stage for testing alternative homogeneity assumptions-including the extent to which parameters' heterogeneity across countries has changed over time. By allowing for contemporaneous and lagged interdependence between open and integrated economies allows for better identification of monetary policy shocks and more realistic description of their transmission mechanism, including their area-wide effects that can be recovered and measured in this framework regardless of the actual degree of heterogeneity present in the data. As far as we know, this is the first study of the European transmission mechanism of monetary policy which allows explicitly for parameters' variation over time.

Obviously, such a framework cannot be estimated without introducing restrictions because of the very large number of parameters involved. Following Canova and Ciccarelli (2000), we address this issue by specifying the econometric model hierarchically (in a sense made clear below) in terms of few hyperparameters and taking a numerical Bayesian approach to estimation. We consider a small group of European countries (Germany, Italy, France, and Spain) and use monthly data from 1985 to 1998. These are the four largest economies currently part of EMU accounting for about $80 \%$ percent of the Euro-area GDP in the period 1980-2000. The econometric specification is the same for all countries considered. We measure monetary policy by estimating an empirical model of the behavior of these countries' central banks, and then assess the impact of monetary policy on economic activity by estimating a system of dynamic output equations as done by Dornbusch and others (1998) and Peersman and Smets (1998). Thus, we do not model nominal exchange rates and inflation rates. We control for both intra-Europe exchange rate movements and heterogeneity of central banks' preferences along the line pursued by Sala (2001) and Clements and Kontolemis (2001), albeit in much simpler manner.

Consistently with the consensus view in the literature, we show that there are crosscountry differences in the transmission mechanism of European monetary policy, both with regards to country specific and common monetary policy shocks. However, we show also that 
these differences are a matter of timing rather than magnitude of their direct effects: the direct cunulative impact of both country specific and common monetary shocks are rather homogenous after two years, especially when parameters' variation across time periods is allowed for. Differently from the consensus view in the literature, and consistently with what suggested by Cecchetti (1999), we show that the transmission mechanism of monetary policy is changing over time in these European countries, but the degree of heterogeneity of these economies' response to monetary shocks is not decreasing. We finally provide evidence on the European-wide impact of monetary policy, showing that its effects take about sixseven months to appear, peak after twelve months, and vanish within 24 months.

The paper is organized as follows. The econometric framework used is presented in section 2 . We report and discuss the estimated monetary policy shocks in section 3 . The empirical evidence on the effects of these shocks on economic activity, and their degree of homogeneity across countries and stability over time, is discussed in section 4 . Sections 5 reports the results on the 'European-wide' impact of monetary policy. Section 6 concludes. Details of the estimation techniques and the data used are given in appendix.

\section{The econometrics}

Ideally, one would like to apply the empirical framework proposed by Canova and Ciccarelli (2000) to a small structural VAR for output, inflation, interest rates, and exchange rates, the set of variables usually considered in the literature. This is feasible in principle, but in practice is extremely demanding computationally while allowing for unconstrained interdependence between countries and variation of parameters over time, given that the posterior distributions of the parameters of interest are integrated numerically in this framework. ${ }^{3}$

Here, we follow the two stage approach used by Dormbusch and others (1998) and Peersman and Smets (1998), and do not model inflation and the exchange rate explicitly. In the

\footnotetext{
${ }^{3}$ We shall discuss the estimation method used in more details below and in the appendix of the paper. Here, however, it is worth noting that substantive constraints could also arise from the interaction of identification and estimation issues as soon as one departs from an exactly identified, completely unrestricted $V A R$ specification. See 2 ha (1999) for a discussion of this point.
} 
first stage, a measure of monetary policy is extracted from the data by estimating a system of reaction functions (one for each central bank) allowing for simultaneity and interdependence in short-term interest rates and parameters' variation across countries and time periods. In the second stage, the impact of monetary policy on economic activity is analyzed by estimating a system of dynamic output equations (again one for each country) allowing also for parameters' variation across countries and time periods, but no simultaneity.

In the following two sub-sections, we present the econometric model of the reaction functions and output equations, the third and the second block of the PVAR above, in turn.

\subsection{Measuring monetary policy}

\subsubsection{Specification}

The behavior of the four European central banks considered is modelled as a system of reaction functions of the type discussed and estimated by Clarida, Gali and Gertler (1997). This system of reaction functions is modelled empirically by means of the following structural $V A R$ :

$$
A_{t}(L) R_{t}=B_{t}(L) W_{t}+D_{t}+U_{t},
$$

where $R_{\imath}=\left[r_{t}^{1}, \cdots, r_{t}^{4}\right]^{\prime}$ is a $(4 \times 1)$ vector of monetary policy instruments, $W_{t}=\left[w_{t}^{1}, \cdots, w_{\varepsilon}^{4}\right]^{\prime}$ is a $(4 \times 1)$ vector of monetary policy final objectives, $A_{t}(L)$ and $B_{t}(L)$ are time-varying polynomial matrices in the lag operator $L$ with lag length $p$, and $D_{t}$ is a $(4 \times 1)$ vector of constants. $U_{t}=\left[u_{t}^{1}, \cdots, u_{t}^{4}\right]^{\prime}$ is a $(4 \times 1)$ vector of monetary policy shocks assumed to be normally distributed with:

$$
\begin{aligned}
E\left[U_{t} \mid Z_{t-s}\right] & =0, \text { for all } t \text { and } s \geq 0 ; \\
E\left[U_{t} U_{t}^{\prime} \mid Z_{t-s}\right] & =I, \text { for all } t \text { and } s \geq 0 ; \\
E\left[U_{t} U_{s}^{\prime}\right] & =0, \text { for all } t \neq s,
\end{aligned}
$$

where $Z_{t}$ contains lagged $R_{t}$ and contemporaneous and lagged $W_{t}, E$ denotes the expectation operator, and $I$ an identity matrix of conforming dimension.

As proxy for the monetary policy instrument we use short-term interest rates. Each element of the $(4 \times 1)$ vector of final objectives, $w_{i t}=\left[\left(\pi_{i, t}-\pi_{i}^{*}\right),\left(y_{i, t}-y_{i}^{*}\right),\left(e_{i t}-e_{i}^{*}\right), \sigma_{i, t}\right]^{\prime}$, 
contains inflation $(\pi)$, output $(y)$ and the nominal exchange rate $(e)$, in percent deviation from target $\left(\pi^{*}, y^{*}, e^{*}\right.$, respectively), and a measure of the (unconditional) intra-month exchange rate volatility $(\sigma)$ to control for shocks to exchange rate risk premia. The actual dimension of $W_{t}$ therefore is $16 \times 1$. Short-term interest rates are measured by the 3 -month Treasury bill rates. Output is measured by an industrial production index, while infiation is measured by the annual change in the consumer price index. We use the bilateral rate vis-a-vis the deutche mark (DM) for France, Italy, and Spain; and the DM/US dollar rate for Germany. Bilateral rates vis-a-vis the DM are obtained as cross rates vis-a-vis the US dollar. The targets variables $\left(\pi^{*}, \mathrm{y}^{*}\right.$, and $\left.e^{*}\right)$ are the fitted values of a regression of the actual variables $\left(\pi_{i, t}, y_{i, t}\right.$, and $\left.e_{i t}\right)$ on a constant and a linear trend, a constant and a quadratic trend, and a simple constant, respectively. ${ }^{4}$

As pointed out by Dornbusch and others (1998, footnote 13), this specification can be interpreted as the reduced form of a forward-looking structural model where contemporaneous and lagged gaps are valid instruments for expected future gaps, or as a system of backward-looking reaction functions. Under the assumption that the central bank's supply of reserves is perfectly elastic, $u_{i, t}$ can be interpreted as the random, or unexpected, component of country specific monetary policy; and hence $\bar{u}_{i, s}$, the estimated residual of (1), in principle, should be equivalent to monetary shocks obtained from standard structural $V A R$ models. Shocks to money demand not fully accommodated by the central bank or exogenous shocks to exchange rate risk premia not fully captured by the volatility variable included in the system, however, may invalidate this interpretation. (See Clarida and others, 1997, for a discussion of this issue.)

The specification chosen imposes very few a-priori restrictions on the system of reaction functions. First, the model allows for contemporaneous and lagged interdependence among short term interest rates of different countries. Second, given that the degree of each member's commitment to ERM has varied over time, we leave $B_{t}\left(L^{P}\right)$ unrestricted and let the data reveal which objective was actually relevant in every particular time period. Similarly,

\footnotetext{
${ }^{4}$ See the data appendix for details on the sources of the data used and the transformations made, including the definition of $\sigma$.
} 
$A_{t}\left(L^{P}\right)$ is unrestricted for all $p \neq 0$. All parameters of the model except those governing the contemporaneous causation among short-term interest rates can thus vary over time, allowing for the possibility of change in central banks' behavior over the sample period considered. ${ }^{5}$ However, we do impose an arbitrary lag length restriction assuming that $p=1$ for all countries and variables considered; thus, assuming that one lag is enough to obtain white noise residuals once we have allowed for contemporaneous and lagged interdependence between countries.

\subsubsection{Identification}

The identification of (1) exploits the Bundesbank's leading role under ERM and the fact that other European countries considered have comparable size. More specifically, to identify the model we place the German short term interest rate first in the vector $R_{t}$, assuming that it affects other European interest rates contemporaneously without being affected by them, and then assume that the impact on country $l$ of an increase in interest rates in country $i$ is the same as the impact on country $i$ of an increase in country $l$ for $i, l=2,3,4$.

Formally, the leader-follower behavior characterizing ERM is translated into the following block recursive structure for $A(0)$, the coefficient matrix of $L^{0}$ in $A_{t}(L)$ :

$$
A(0)=\left[\begin{array}{ll}
A_{11}(0) & 0 \\
A_{21}(0) & A_{22}(0)
\end{array}\right]
$$

where $A_{11}(0)$ is a scalar, $A_{21}(0)$ is $3 \times 1$, and $A_{22}(0)$ is $3 \times 3$. This gives us three restrictions. The remaining three restrictions needed to identify the model are obtained by imposing that $A_{22}(0)$ is symmetric. These six restrictions identify the model exactly regardless of the order of the non-German interest rates in $R_{\mathrm{t}}{ }^{6}$

The structural $V A R$ model (1), therefore, can be rewritten as:

$$
\left[\begin{array}{ll}
A_{11}(0) & 0 \\
A_{21}(0) & A_{22}(0)
\end{array}\right]\left(\begin{array}{l}
R_{t}^{1} \\
R_{t}^{2}
\end{array}\right)=\left[\begin{array}{ll}
A_{11}(L) & A_{12}^{\prime}(L) \\
A_{21}(L) & A_{22}(L)
\end{array}\right]_{t}\left(\begin{array}{l}
R_{t-1}^{1} \\
R_{t-1}^{2}
\end{array}\right)
$$

\footnotetext{
${ }^{5}$ Assuming that the coefficient matrix of $L^{0}$ in $A(L)$ is constant over time renders the posterior distributions analytically tractable and is equivalent to assume homoschedaticity of the structural residuals.

${ }^{6}$ See Amisano and Giannini (1997, p. 166-67).
} 


$$
+\left[\begin{array}{cc}
B_{11}(L) & B_{12}(L)^{\prime} \\
B_{21}(L) & B_{22}(L)
\end{array}\right]_{t}\left(\begin{array}{c}
W_{t}^{1} \\
W_{t}^{2}
\end{array}\right)+D_{t}+\left(\begin{array}{c}
U_{t}^{1} \\
U_{l}^{2}
\end{array}\right)
$$

where $R_{t}^{1}, W_{t}^{1}$, and $U_{t}^{1}$ are the German monetary policy instrument, objectives, and shock, respectively; while $R_{t}^{2}, W_{t}^{2}$, and $U_{t}^{2}$ are the vectors containing the same variables for France, Italy, and Spain.

\subsubsection{Estimation}

Bayesian estimation of (3) exploits its block recursive structure.

Following Zha (1999), let $k_{j}$ and $G_{j}$ be the total number of right-hand-side variables per equation and the total number of equations in block $j$ of (3), respectively, whereas the same set of variables enter the equations of each block $j$. If we pre-multiply (3) by the ( $4 \times 4)$ matrix

$$
A_{d}^{-1}(0)=\left[\begin{array}{ll}
A_{11}^{-1}(0) & \sigma^{\prime} \\
0 & A_{22}^{-1}(0)
\end{array}\right],
$$

and rearrange terms, the model can divided in two blocks and written as:

$$
R_{t}^{j}=Z_{t}^{j} \delta_{t}^{j}+v_{t}^{j} \quad j=1,2, \text { for all } t .
$$

Here, $Z_{t}^{j}=\operatorname{diag}\left[Z_{1, t}^{j}, Z_{2, t}^{j}, \ldots, Z_{G_{j, t}}^{j}\right]$ denotes a $\left(G_{j} \times k_{j} G_{j}\right)$ diagonal matrix whose elements are the $\left(1 \times k_{j}\right)$ vectors, $Z_{g, c}^{j}$, containing all contemporaneous (in our case only $R_{t}^{1}$ in block 2 ) and lagged endogenous variables, exogenous and deterministic variables, of equation $g$ in block $j$ for $g=1, \ldots, G_{j} ; \delta_{t}^{j}=\left[\delta_{1, t}^{j}, \delta_{2, t}^{j}, \ldots, \delta_{G_{j, t}}^{j}\right]$ denotes a $\left(k_{j} G_{j} \times 1\right)$ vector whose $\left(k_{j} \times 1\right)$ elements, $\delta_{g, t}^{j}$, contain the parameters of equation $g$ in block $j$ for $g=1, \ldots, G_{j}$; and $v_{t}^{j}=A_{j j}^{-1}(0) U_{t}^{j}$ with

$$
v_{i}^{j} \sim N\left(0, \Sigma_{j j}\right), \Sigma_{j j}=A_{j j}^{-1}(0) A_{j j}^{-1}(0)^{\prime} \text {, and } E\left[v_{t}^{i} v_{t}^{j^{\prime}} \mid Z_{t-8}\right]=0 \text { for } i \neq j .
$$

Note that, given the identification assumptions above, the first block $(j=1)$ of $(4)$ contains only one equation that represents the reaction function of the Bundesbank. The second block $(j=2)$ contains three equations, representing the reaction function of the Bank of France, the Bank of Italy, and the Bank of Spain respectively. In our case, therefore, we have $k_{1}=37$ and $k_{2}=38$, whereas the larger number of parameters in the second block takes 
into account the contemporaneous effect of the German interest rate in the reaction function of others central banks. In fact, the number of lagged endogenous variables is 4 in both blocks, the number of exogenous variables-which enters the system of reaction functions both contemporaneously and with lags-is also 16 in both blocks, and there is only one lag and a constant.

Bayesian estimation of the two blocks of (4) is then obtained by means of Kalman filter and Gibbs sampling techniques modified as suggested by Chib and Greenberg (1995) to take into account the presence of time variation in the model's parameters, as in Canova and Ciccarelli (2000): a joint prior on $\left(\delta_{t}^{j}, \Sigma_{j j}\right)$ is combined with the likelihood of the data and suitable initial parameters values to recover the posterior distributions of interest by numerical integration. Since the matrices $A_{j j}(0)$ are exactly identified, and thus linked to $\Sigma_{j j}$ by a one-to-one mapping, we can recover the posterior distribution of the structural parameters of the model, and hence the posterior distribution of the structural residuals $\left(U_{t}\right)$ from the estimate of the model's reduced form for each iteration of the Gibbs sampler. The average of the empirical distribution of these residuals is then taken as our measure of the random or unexpected component of monetary policy. ${ }^{7}$

\subsection{The transmission mechanism of monetary policy}

\subsubsection{Specification}

The impact of monetary policy on economic activity is modelled empirically through a system of output equations in which annual output growth is regressed on our measure of the unexpected component of monetary policy and a set of control variables. For each country $i$, we specify the following equation:

$$
y_{i t}=X_{i t}^{\prime} \beta_{i t}+\varepsilon_{i t}
$$

where $y_{i t}$ is the 12-month growth of industrial production, $X_{i t}^{\prime}=\left[\widehat{u}_{i t-l_{i}}, x_{i t}\right]^{\prime}$ is a $(1 \times k)$ vector of regressors with $\widehat{u}_{i t-l_{i}}$ denoting lags of the series of estimated monetary policy shocks and

\footnotetext{
7See appendix for more details on Bayesian estimation of (4), incl uding relative tightness of the model's hyperparameters.
} 
$x_{i t}$ denoting the set of control variables, $\beta_{i t}=\left[\beta_{i t}^{1}, \beta_{i t}^{2}\right]^{\prime}$ is a $k \times 1$ vector of parameters with $\beta_{i t}^{1}$ and $\beta_{i t}^{2}$ denoting the coefficients of $\hat{u}_{i t-l_{i}}$ and $x_{i t}$ respectively. In $x_{i t}$, we include lagged output growth of all countries considered to capture regional interdependencies, the first lag of the nominal exchange rate of country $i$ vis-a-vis the DM and the US dollar to hold constant the intra-Europe exchange rate channel of transmission of monetary policy, and the lagged inflation rate of country $i$ to control for supply-side factors affecting economic activity. These restrictions are imposed to save computing time in the numerical integration and they could be relaxed without facing other constraints. The econometric specification is the same for all countries considered and includes, in addition to the variables already mentioned, a constant and 24 lags of $\hat{u}_{i t-l_{i}}\left(l_{i}=1,2, \ldots, 24\right)$, for a total of 31 regressors in each equation.

The econometric specification of (5) allows $\beta_{i t}$ to vary randomly both across countries and time periods, though only as different draws from the same exchangeable distribution. This is achieved by assuming that $\beta_{i t}$ is a random variable drawn from a common prior distribution, which changes also randomly over time according to a given and common law of motion, whereas both distributions are assumed to be exchangeable. This hierarchical structure of the prior distributions with exchangeability is both mathematically tractable and economically plausible in the absence of additional prior information on the nature of the parameters' variation over countries and time periods.

Formally, for each country $i$ and time $t$, we assume that:

$$
\begin{aligned}
\beta_{i t}=\theta_{t}+\zeta_{i t} & \zeta_{i t} \sim N\left(0, b_{o}\right), \\
\theta_{t}=\theta_{t-1}+\eta_{t} & \eta_{t} \sim N\left(0, B_{1}\right) ;
\end{aligned}
$$

Here, $b_{o}$ and $B_{1}$ denote the variance of the distribution of $\zeta_{i t}$ and $\eta_{t}$ respectively. $B_{1}$ controls the time-variation of the prior mean of the parameters, whereas $b_{0}$ controls their variation around the mean both across countries and over time..$^{\mathrm{s}}$ If $B_{1}=0, \beta_{i t}=\theta+\zeta_{i t}$ for all $t$, and

\footnotetext{
${ }^{8}$ The specification of the law of motion of $\theta_{t}$ in $(7)$ implies that the parameters have an unconditional mean equal to zero. An al ternative specification is:
}

$$
\theta_{t}=\rho \theta_{t-1}+(1-\rho) \bar{\theta}+\eta_{t},
$$


the parameters vary randomly over countries and time periods around a constant mean. On the other hand, if $b_{o}=0, \beta_{i t}=\theta_{t-1}+\eta_{t}$ for all $i$. In this case, no cross sectional heterogeneity is present, and $\beta_{i t}$ is shrunk towards a common time-varying mean. If both $B_{1}$ and $b_{o}$ are zero, $\beta_{i t}=\theta$ for all $i$ and $t$ and the prior distribution of the parameters degenerate in a common constant. The prior variances of $\eta_{t}$ and $\zeta_{i t}$, therefore, provide a way to control the degree of prior uncertainty introduced in the model on how the parameters of interest may change over countries and time periods. ${ }^{9}$

The assumptions (6-7), however, are only priors which must be combined with the data to generate posterior distributions of the parameters of interest. The moments of the posterior distributions of $\beta_{i t}$ do not need to be the same as those characterizing the priors, as indeed we shall see by looking at the empirical results reported below. Note particularly that, while the prior variance of $\beta_{i t}\left(b_{o}+B_{1}\right)$ is time-invariant, the posterior variance of $\beta_{i t}$ may changes over time due to realizations of both $\eta_{t}$ and $\zeta_{i t}$ (See equation (21) in appendix on this). The assumptions in (6-7), therefore, permit clearly to check whether or not the degree of heterogeneity of the parameters of the transmission mechanism of monetary policy has changed over time. Note also that, with this specification, the posterior mean of $\theta_{t}$ can be interpreted as the area-wide relation.

\subsubsection{Estimation}

Stacking all equations by row and rewriting (5) as a standard system of seemingly unrelated regressions (SUR) we have:

$$
y_{t}=X_{t} \beta_{t}+\varepsilon_{t}, \quad \varepsilon_{t} \sim N_{g}(0,-) .
$$

where $\bar{\theta}$ is the long run mean of $\theta_{t}$. However, when we estimated the hyperparameter $\rho$ by maximizing the sample likelihood in (8) below for each country $i$, we found values for $\rho$ ranging from 0.9985 for Spain to 1 for France and Ytaly. Given this evidence, we decided to stick to the computationally simpler specification in $(6)$.

${ }^{9}$ The specification in (6) is similar to the one used by Canova and Ciccarelli (2000). The main difference is that they split the parameter vector $\beta_{i t}$ in two independent components: one is unit specific $\left(\zeta_{i}\right)$ and the other varies commonly over time $\left(\lambda_{t}\right)$. Unlike them, we do not identify the unit specific effect separately and lump it together with the idiosyncratic component $\left(\zeta_{i t}\right)$. Given independence between the country specific effect $\zeta_{i}$ and the time-varying common component $\lambda_{t}$, the specification used by Canova and Ciccarelli (2000) would not allow to test for persistence of cross country differences over time because the posterior variance of $\beta_{i t}$ would be time-invariant. 
In this system $X_{t}=\operatorname{diag}\left[X_{1 t}^{\prime}, \ldots, X_{G t}^{\prime}\right]$ is of dimension $G \times h$, where $h=G * k$, with $G=4$ denoting the number of endogenous variables and and $k=31$ denoting the number of regressors in each equation, while $\beta_{t}=\left[\beta_{1 t}, \ldots, \beta_{g t}\right]^{\prime}$ is of dimension $h \times 1$.

The assumptions on the prior distribution of the parameters' vector $\beta_{t}$ can then be restated as:

$$
\begin{array}{rlrl}
\beta_{t}=M_{o} \theta_{t}+\zeta_{t}, & & \zeta_{t} \sim N_{h}\left(0, B_{o}\right) \\
\theta_{t}=\theta_{t-1}+\eta_{t}, & \eta_{t} \sim N_{m}\left(0, B_{1}\right)
\end{array}
$$

where the $(h \times k)$ matrix $M_{o}$ is a column vector of $G$ identity matrices of order $k$ that relates $\beta_{t}$ to the $(k \times 1)$ vector of common shift parameters $\theta_{t}$, and - , $B_{o}$, and $B_{1}$ are unknown variance-covariance matrices of $\varepsilon_{t}, \zeta_{t}$ and $\eta_{t}$, respectively. The latter three random vectors are assumed mutually independent, implying that $y_{t}$ is conditionally independent of $\theta_{t}, B_{o}$, and $B_{1}$.

Bayesian estimation of the hierarchical model (8-10) is then performed by means of Kalman filter and Gibbs sampling techniques, modified as suggested by Chib and Greenberg (1995) to take into account the presence of time variation in the model's parameters, as in Canova and Ciccarelli (2000): prior assumptions are set on the hyperparameters of the model $\left(-, B_{o}, B_{1}\right)$ and combined with the information contained in the data (in the form of a likelihood function and initial conditions) to obtain posterior distributions. As in the case of the estimation of the reaction functions, analytical integration is not feasible, and the Gibbs sampler is used to compute posterior distributions of the parameters of interest numerically.

\subsubsection{Testing}

Several hypotheses of parameter homogeneity can be performed on the posterior distributions of the parameters of interest. We are particularly interested in the overall degree of stability over time of the posterior distributions of the parameters of the transmission mechanism of monetary policy, their degree of heterogeneity across countries, and any tendency of this heterogeneity to change over time. More specifically, we want to test the absence of time variation in the common component $\theta_{t}$ and the null hypothesis that the transmission 
mechanism is homogeneous across countries, either over the entire sample or in each yearly subperiod considered.

The first hypothesis can be tested by letting $B_{1}$ depend upon two hyperparameters, $\phi_{1}$ and $\phi_{2}$; the first controlling for the time variation of the monetary policy parameters and the second for the time variation of other parameters. If the posterior distribution of $\phi_{1}$ is concentrated around values closer to zero than its prior, then the evidence supporting a time-varying specification (at least for the monetary policy parameters) would be weak. Thus, testing the null hypothesis that $\phi_{1}=0$ may be seen as a specification test for the model used. This is checked by following Chib and Greenberg (1995) and calculating, for arbitrarily small values of $\xi$, the ratio:

$$
z=\frac{\operatorname{Pr}(\phi \leq \xi \mid y) \operatorname{Pr}(\phi>\xi \mid y)}{\operatorname{Pr}(\phi \leq \xi) \operatorname{Pr}(\phi>\xi)},
$$

where $\operatorname{Pr}(\phi \leq \xi \mid y)$ and $\operatorname{Pr}(\phi \leq \xi)$ denotes the conditional posterior probability and unconditional prior probability that $\phi$ is less than $\xi$, respectively. The numerator of this ratio is computed from the relative frequencies generated by the Gibbs sampler, while the denominator is given by the prior assumption.

The presence of cross country differences in the transmission mechanism of monetary policy is tested by using a procedure proposed by Ciccarelli (2000) that is an empiricalBayesian analogous of the classical Wald-test. In the classical Wald test, one compares two quadratic forms: one asymptotically distributed as a $\chi_{(d)}^{2}$ under the null assumption that is assumed to hold exactly, and the other distributed as a non-central $\chi_{(d)}^{2}$ under the alternative; the greater the numerical value of the quadratic form in which the exact restrictions have been substituted, the more likely is that the value drawn belongs to the distribution under the alternative hypothesis. The main difference with respect to the classical Wald test is that, here, we know the exact distribution of the quadratic form under the null assumption, while the null hypothesis is formulated as a probabilistic statement about the posterior distribution of a linear (or possibly non linear) function of the parameters of interest. The exact distribution of the quadratic form under the null hypothesis becomes a 'reference' distribution, which can be sampled numerically by means of Gibbs sampling and used to 
make probabilistic assessments in a Bayesian way about a given set of restrictions.

Write the null hypothesis of homogeneity of the parameters of interest as a general set of restrictions on the parameter vector $\beta_{t}$

$$
\mathrm{R}\left(\beta_{2}\right)=\mathrm{r}, \text { for each } t \text {. }
$$

where $R\left(\beta_{t}\right)$ is a vector of possibly non linear function of $\beta_{t}{ }^{10}$ Conditional on other par rameters of the model and given the specification above, the posterior distribution of $\beta_{t}$ is:

$$
\left.\beta_{t} \sim N\left(\hat{\beta}_{t}, \hat{-}\right)_{t}\right) .
$$

Thus, the conditional posterior distribution of a linearized version of $R\left(\beta_{t}\right)$ is approximately distributed as follows:

$$
\mathrm{R}\left(\beta_{t}\right) \sim N\left(\mathrm{R}\left(\hat{\beta}_{t}\right), \nabla \mathrm{R}\left(\hat{\beta}_{t}\right)^{\prime}={ }_{t} \nabla \mathrm{R}\left(\hat{\beta}_{t}\right)\right) .
$$

where $\nabla R\left(\hat{\beta}_{t}\right)$ denotes the gradient of the vector $R\left(\beta_{\imath}\right)$ computed at $\hat{\beta}_{t}$.

The test is based on the comparison of these two quadratic forms:

$$
q_{t}=\left(\mathrm{R}\left(\beta_{t}\right)-\mathrm{R}\left(\hat{\beta}_{t}\right)\right)^{\prime}\left(\nabla \mathrm{R}\left(\hat{\beta}_{t}\right)^{\prime}{ }^{-}{ }_{t} \nabla \mathrm{R}\left(\hat{\beta}_{t}\right)\right)^{-1}\left(\mathrm{R}\left(\beta_{t}\right)-\mathrm{R}\left(\hat{\beta}_{t}\right)\right)
$$

and

$$
q_{1 t}=\left(R\left(\beta_{t}\right)-r\right)^{\prime}\left(\nabla R\left(\hat{\beta}_{t}\right)^{\prime}-{ }_{t} \nabla R\left(\hat{\beta}_{t}\right)\right)^{-1}\left(R\left(\beta_{t}\right)-r\right) .
$$

If the posterior distribution of $R\left(\hat{\beta}_{t}\right)$ is centered on $\mathrm{r}$-i.e., in the limit the restrictions (12) are true with probability 1 and $R\left(\hat{\beta}_{t}\right) \equiv r-q_{1 t}$ must have the same distribution as $q_{t}$; otherwise, it is conditionally distributed as a non-central distribution with respect to the distribution of $q_{t}$. In order to construct a rejection region for the null hypothesis, therefore,

\footnotetext{
${ }^{10}$ In the specific case of linear restrictions, the restriction matrix $R=\left[R_{i, j}\right]$ has dimension $d \times G k$, where $G$ and $k$ have been defined before, $d=(G-1) p_{m}$, and $p_{m}$ is the number of monetary policy coefficients restricted to be the same across countries. In particular, the null hypothesis that all parameters of the tranamission mechanism are equal implies $p_{m}=24$. In this case, $R$ has 72 rows, whose values are 1 when $i=j,-1$ when $j=i+k$, and 0 otherwise. The hypothesis that the impact of monetary policy at specific lags, or its cumulative effect after one or two years, are equal across countries can also be easily accommodated designing $R$ accordingly.
} 
it is enough to compare these two distributions: the larger the distance between $q$ and $q_{1}$, the more likely is that the restrictions imposed are converting the reference distribution in a non-central distribution, and thus the greater is the probability, a posteriori, that the null hypothesis is false. The empirical posterior distributions of $q$ and $q_{1}$ are easily obtained from the Gibbs sampler. The distance between these two distributions can then be quantified using a standard Kolmogorov-Smirnov statistics. ${ }^{11}$

Note finally that, if the model is specified with time-varying parameters, we can easily compute empirical distributions for $q$ and $q_{1}$ and quantify their distance for each subperiod considered. Thus, we can test the null hypothesis of parameter homogeneity across countries for each subperiod considered. The time profile of the Kolmogorov-Smirnov statistic measuring the distance between the two distributions, therefore, can give a clear indication of the direction of change of the differences across countries in the parameters of the transmission mechanism (if any is found).

The illustration of the procedures used to test the homogeneity and stability of the transmission mechanism of European monetary policy concludes the presentation of the econometric framework. The next three sections discuss the empirical results.

\section{Estimated monetary policy shocks}

In this section we report the residuals derived from estimation of (3), our measure of the unexpected component of monetary policy which will be used in the rest of the paper. The data sample used is January 1985-December 1998. The Kalman filter is initialized using the first five years of data (through December 1990). The estimated residuals, therefore, run from January 1991 to December 1998.

The posterior distributions of the parameters of the reaction functions of each central bank considered are not reported here because of space constraints, but are available on

\footnotetext{
${ }^{11}$ See Ciccarelli (2001) for more details. When evaluated by means of Monte Carlo simulations, this procedure scores well in terms of both power andsize, doing better than the posterior odds (PO) ratio test when the prior is informative. In addition, it is easier to implement and, unlike the PO ratio tes: can be computed also when some of the prior distributions in the hierarchy are diffuse.
} 
request. Ciccarelli and Rebucci (2000) discuss in details this part of the empirical analysis and show that these posterior distributions are symmetric and generally have means with the expected signs. They show also significant parameter time variation, especially until 1992-93 for Germany and 1994-1995 for other countries. Exchange rate volatility appears to matter for all countries considered. Germany's seerns to have reacted mainly to domestic objectives, even though the volatility of the DM has also coefficients clearly different from zero. The time profile of these coefficients, in particular, suggests that the Bundesbank's attention has shifted in the run up to EMU from the dollar value of the DM to the external value of the DM vis-a-vis other European currencies. France, Italy, and Spain seerns to have had different reaction functions. All three reaction functions, however, react strongly to contemporaneous movements in German interest rates. The behavior of the central bank of Spain is the most peculiar: Spain appears to be the country least constrained by EMS, with its own output gap affecting short term interest rates throughout the period considered; moreover, the exchange rate gap vis-a-vis the DM has a persistently negative sign, while the coefficient of the volatility of the bilateral rate against the US dollar is positive throughout the estimation period, even though slightly trending downward. ${ }^{12}$

The estimated structural residuals of equation (3)-our measure of a local or country specific monetary policy shock-are plotted in Figure 1 and look remarkably well behaved: there are very few outliers (most notably a large one for France in April 1993) and there is little evidence of autocorrelation and/or heteroscedasticity. Note that experimenting with a higher number of lags only for Germany, we found very similar results suggesting that the remaining autocorrelation is not due to a short lag length (results not reported). At the same time, when we estimate (3) without exchange rate volatility and restricting $B(L)$ as done by Dornbusch and others (1998) we find residuals very much like theirs (Figure 4) with large outliers at about the same dates, further suggesting that adding exchange rate volatility and letting $B(L)$ unrestricted helps obtaining better residuals, and thus cleaner monetary policy shocks.

\footnotetext{
${ }^{12}$ Spain's peculiar behavior is a feature our results shared with other studies of the transmission of real and monetary shocks in the Euro area, including for example Kim (1998), Ballabriga et al. (1999), and Ortega and Alberola (2000).
} 
The structural residuals of (3) can be used to compare across countries the transmission mechanism of country specific monetary shocks. These shocks reflect, or are the result of, each country's individual preferences over the set of possible monetary policy objectives. However, a key feature of EMU is that individual members' preferences and reaction functions have been substituted by, or aggregated into, those of the ECB and its policymaking bodies. ${ }^{13}$ In order to approximate as closely as possible conditions prevailing under EMU, one would also like to investigate the response of these economies to common shocks-i.e., shocks that reflects the aggregation of countries' preferences over the possible objectives of monetary policy.

In our econometric framework, a common monetary policy could be defined either constraining the transmission mechanism of country specific monetary shocks through restrictions on (8) below as done by Dornbusch and others (1998), or by extracting common monetary shocks from country specific data from (3) as done by Sala (2001), or by identifying directly monetary policy under EMU with German monetary policy under ERM as done by Clements and Kontolemis (2001). Given the difficulties of identifying common monetary policy shocks in (3) (other than simply identifying them with those obtained from the German reaction function), and the computational costs of imposing restrictions on the transmission mechanism of country specific shocks in (8), we have followed a straightforward principal component analysis appro.4ch and, as a measure of a common monetary policy, we have taken the first princlpal cumponent of the reduced form residuals (i.e., non orthogonalized residuals) of (3). ${ }^{14}$

Even though this measure might be crude, it should provide at least a term of comparison for our analysis of the effects of country specific shocks. The normalized first principal component of the reduced form residuals (also reported in Figure 1) explains about 50 percent of their total variation, about 25 percent of the residual of the Bundesbank's reaction function, about 10 percent of the Bank of France's reaction function, and about 50 percent

\footnotetext{
${ }^{13} \mathrm{See}$ Clements and Kontolemis (2001) for a more rigorous analysis of this point.

${ }^{14}$ Principal component analysis is a standard econometric technique to extract common components from series of data. See Theil (1971), for a standard reference. Note that estimation of the reduced form of this model is identical to that of the structural form described in the text, except that it is not done by blocks.
} 
of the residuals of the reaction functions of the Bank of Italy and the Bank of Span. Its simple correlation with the residual of the Bundesbank's reaction function is 0.24 .

\section{The impact of monetary policy in individual coun- tries}

In this section we present parameter estimates and test statistics of the output equations that describe the impact of monetary policy on economic activity. The series of estimated monetary policy shocks run from January 1991 to December 1998. Since we include 24 lags of this variable, the data sample for the estimation of the output equations starts only from January 1993.

Even though we have estimated all parameters of the system of output equations (8), we present only the results for the posterior distribution of the sub-vector of monetary policy coefficients, $\beta_{i t}^{1}$, and their estimated average or common component, $\theta_{t}$, which we interpret as the European-wide impact of monetary policy. We present four set of estimation and testing results: two sets based on the estimation of (8) specified without parameter time variation to compare these results to those previously found in the literature; and two set based on (8) estimated with time-varying parameters. Both the time-varying and the time-invariant specification is estimated including, in turn, only $\hat{u}_{\text {it }}$ (the vector of countryspecific structural residuals, which we interpret as a local monetary policy shock) and $\hat{u}_{t}$ (the principal component of the reduced form residuals, which we interpret as a common monetary policy shock).

In order to save computing time and to facilitate the results' interpretation, the timevarying specification actually estimated allows the parameter vector to change only yearly, while in fact we use monthly data (see Appendix for details). The type of behavioral change we are interested in-presumably induced by anticipation of and preparation to EMUis likely to have taken place over time rather slowly, and hence some time aggregation in estimating the parameters of the transmission mechanism of monetary policy might be desirable. In any case, we are not interested in isolating changes at monthly frequency. In 
addition, when the model is estimated without imposing this restriction only for Germany and Spain, we find very similar results (not reported), suggesting that the results presented below are robust to this feature of the specification actually used.

\subsection{Are there differences across countries in the transmission mech- anism of monetary policy?}

In order to compare our results with those in the literature, in this subsection, we report time-invariant estimates of the system of output equations and we test several homogeneity hypothesis on the transmission mechanism of country specific and common monetary policy shocks. Table 2 reports the mean, the median, the first and the third quartile of the posterior distribution of the coefficients of $\hat{u}_{i \varepsilon}$. For all countries considered, the table reports the coefficients of selected lags and the cumulative direct effect after one and two years respectively.

From Table 2, we can see that the effects of country specific monetary policy shocks become evident within 18 months in all countries considered, and that there are some cross country differences in the impact at particular lags, but basically no quantitative differences with respect to their direct cumulative impact as far as Germany, France, and Italy are concerned. The effects of country specific monetary policy shocks on output growth in Spain, instead, seem to be different from those in other countries both in terms of their timing and cumulative direct impact, which is lower.

These conclusions are borne out clearly also by a formal testing of various homogeneity assumptions. Table 3 reports a set of Kolmogorov-Smirnov statistics (henceforth, KS) for the distance between the posterior distribution of $q$ and $q_{1}$ under the corresponding null hypothesis. As explained before, a posterior distribution of $q_{1}$ far apart from that of $q$ can be interpreted as evidence against the null of equality of the relevant parameters of interest. When we test the null of equality of all the parameters of the transmission mechanism of country specific monetary shocks, either between all countries considered or through pairwise comparisons (see the column of p-values under 'all lags' in Table 3), we reject the null decisively. This points to the existence of statistically significant difference in the trans- 
mission mechanism of European monetary policy across countries. Running the same test for each pair of countries considered on selected lags and the cumulative direct impact of monetary policy after 12 and 24 months (see the corresponding columns of p-values in Table 3 ), however, we find that the difference between these four countries is mainly due to Spain. Thus, suggesting that the transmission mechanism of country specific monetary shocks in France, Italy, and Germany might have already been rather homogenous on the onset of EMU, especially as far as the cumulative effects are concerned. As for Spain, it is possible that these differences are due to a very different reaction function, which could generate very different shocks. It is therefore interesting to compare these results with those obtained including only $\hat{u}_{\boldsymbol{r}}$.

Turning then to the analysis of the transmission mechanism of a common monetary policy shock, as measured roughly by $\hat{u}_{\mathrm{t}}$, we can see from Table 4 and 5 that the results are broadly similar to those obtained for country specific shocks. Somewhat surprisingly, the direct cumulative impact after two years is now higher in Spain than in other countries. This is similar to what found by Ortega and Alberola (2000), who attribute the different response of Spain to a (temporary) common monetary policy shock to its larger sensitiveness to changes in competitiveness vis-a-vis its European partners. According to Alberola and Ortega, the other three European countries, instead, are more sensitive to the wealth effects of interest rate changes. The bilateral differences between Germany, France and Italy are also slightly larger when assessed using a common shock-as measured by lower $\mathrm{p}$-values in Table 5. This latter result suggests that the differences in the transmission mechanism of monetary policy remains significant even after controlling, albeit roughly, for heterogeneity of national central banks' preferences. The fact that the magnitude of the cumulative direct impact of common monetary policy shocks is smaller than that of country specific shocks, instead, may be due to its not large correlation with the German interest rate.

A direct comparison of our results with those obtained in other studies is difficult because of the peculiarities of the empirical framework used in this paper. Nonetheless, Table 6 and 7 attempt to do this, to the extent possible, contrasting the ranking implied by our results with those surveyed by Guiso et al. (2000) and a few comparable point estimates. On 
the one hand, none of our estimate appears far away from what previously reported in the literature, giving confidence that our results are not systematically biased by the peculiar features of the empirical framework used. In particular, when we estimate the model with a specification essentially equivalent to that of Dornbusch and others (1998) and including only the anticipated component of monetary policy and the same data we find very similar results to theirs (Table 6). On the other hand, when we use our preferred specification, a few sharp differences with the previous literature stand out. First, comparing our implied ranking with those obtained with small scale structural VAR models estimated country by country (Table 7)-which are based on impulse response function analysis-we can see that our estimated short-term impact of monetary policy is at the lower end of those previously found, though the resulting ranking is the same as in the literature. This is not surprising given that our specification control for lagged output growth of all countries considered, thereby providing a better description of the international transmission mechanism of monetary policy. Second, unlike Dornbusch and others (1998)-who analyze only the effects of anticipated changes in monetary policy - we do find more evidence of heterogeneity in the short term impact of monetary policy, than with regards to the cumulative direct effects that is the denominator of the long-term impact. Finally, our estimated peak effect and the long run impact are very close to those reported in the BIS study.

In summary, and in part consistently with the consensus view in the literature, the evidence presented so far points to some degree of heterogeneity across countries in the transmission mechanism of monetary policy, especially with regards to the timing of the effects rather than the magnitude of their direct cumulative impact. In fact, only Spain's response to both a local and common monetary policy shock appears significantly different from that of the other European countries considered.

Nonetheless, differences in the timing of the effects of monetary policy in are also important from both a methodological and a policy point of view as explained in the introduction. Therefore, the question of whether or not the degree of heterogeneity of the transmission mechanism of monetary policy has changed over time-and, if this were the case, in which particular direction - remains relevant. 


\subsection{Are these differences changing over time?}

To answer this question, we reestimate the system of output equations (8) allowing for parameter variation over time and test the null hypothesis that the posterior variance of the third stage of the hierarchy (8-10) is zero, i.e., we test the hypothesis that $\phi_{1}$, the hyperparameter tightening the time variation of the coefficients describing the transmission mechanism of monetary policy, $\beta_{i t}^{1}$, is zero.

This is done using the test statistic (11) explained in section (2.2.3). As mentioned above, if the posterior distribution of $\phi_{1}$ is less concentrated on values close to zero than the prior distribution, then we can reject the null of overall parameter stability over time; and thus reject a time-invariant specification of (8). In fact, the value of $z$ in (11), for $\xi=0.03$, is 0.465 in the case of country specific monetary shocks and 0.012 in the case of a common shock. For $\xi=0.05, z$ takes on a value of 1.838 and 0.054 , respectively. ${ }^{15}$ Very small values of $z$ for arbitrarily small values of $\xi$ imply that the posterior distribution of $\phi_{1}$ is located more far away from zero than the prior distribution, providing clear evidence in favor of a time-varying specification for the monetary policy parameters, and thus suggesting that the transmission mechanism of monetary policy has changed over time.

Given that the transmission mechanism of monetary policy seems to have changed over time, we check whether or not its degree of heterogeneity across countries has also changed in the run up to EMU. This is done by running a battery of KS statistics on the posterior distributions of $q$ and $q_{1}$, under the relevant null hypothesis, as in Table 3 and 5 , for each yearly subperiod considered. Table 8 and 10 report the results for all countries considered from 1994 to 1998 for a country specific and a common shock respectively.

As we can see from Table 8 , in the case of a country specific monetary shock, there is some evidence of decreasing distance between the benchmark distribution of $q$ and the posterior distributions of $q$. But the overall picture is one of neither decreasing nor increasing heterogeneity, but rather simple persistence. Nonetheless, we now accept the null hypothesis of equality of the cumulative direct effects of monetary policy after 12 and 24 months between

\footnotetext{
${ }^{15}$ Values for $\xi$ have been chosen arbitrarily small, as in Chib and Greenberg (1995).
} 
all countries considered, including Spain, while this assumption was clearly rejected by the data when tested over the entire period 1991-1998 (cfr. Table 3). It is possible, therefore, that some convergence might have taken place in the first half of the $1990 \mathrm{~s}^{16}$

An inspection of the posterior distributions of the parameters of interest country-bycountry (Table 9), confirms that the short-term effects of country specific monetary shocks are heterogenous, but their cumulative direct impact becomes quite similar across countries after about 12 months. Furthermore, note that the cumulative impact after 12 months is increasing over time while the impact after two years is decreasing in all countries considered. This suggests that the length of the transmission mechanisms was becoming shorter in the second half of the 1990s in all countries considered, possibly, as a result of financial developments and gradually increasing labor market flexibility at the regional level.

In the case of common monetary policy shocks (Table 10 and 11) we obtain similar results: the overall degree of heterogeneity of the transmission mechanism does not appear to decrease over time, but the direct cumulative impact of these shocks turns also out to be homogeneous after 12 months. Interestingly, the value of the third quartile of the distribution of the direct cumulative impact of these shocks after 24 months is always positive, and slightly decreasing over time. This suggests that the posterior distribution of these parameters becomes progressively less concentrated on negative values, which in turn could be interpreted as evidence of increasing degree of monetary policy neutrality in the long run. At the same time the direct impact after 12 -month of common shocks is increasing slightly over time, as found in the case of country specific shocks. The magnitude of the effects of a common shock, finally, looks also rather smaller than that of country specific shock, as found estimating the system of output equations without time variation.

In summary, these results show that the hypothesis of overall parameter stability is rejected by the data: the transmission mechanism of European monetary policy seems to have changed in the second half of the 1990s - possibly becoming shorter-but its degree of heterogeneity across countries has neither increased nor decreased during this period. On the other hand, the results presented suggest also that some convergence might have taken

\footnotetext{
${ }^{16}$ These tests can be run only starting in 1994 because of the observations missed to initilize the estimation.
} 
place in the first half of the 1990s given that the null hypothesis of equality of the direct cumulative effects of monetary policy between all countries considered cannot be rejected by the data when the econometric model is estimated allowing for parameters' variation over time after January 1994. Consistently with these results, Spain's apparently different behavior, found analyzing the effects of idiosyncratic and common shocks over the period 1991-1998 without allowing for time variation, could be explained as the consequence of an econometric specification error.

\section{The European-wide impact of monetary policy}

The evidence presented so far supports the view that the effects of monetary policy on economic activity in these European countries differ in terms of their timing, though not in terms of their direct cumulative effects. A study of the 'European-wide' effects of monetary policy in the sense of Tristani and Monticelli (1999)-i.e., the study of the effects of monetary policy in the Euro-area - based on averages of country specific time series, or standard pooled estimators, may therefore be biased potentially. Moreover, we have seen also that, in the specific case of Spain, a time invariant specification yields very different results from those obtained allowing for the parameters to change over time.

Within the empirical framework used in this study, the European-wide effects of monetary policy are measured by the posterior distribution of $\theta_{t}$, the cross sectional mean of $\beta_{i t}$. Tables 12 and 13 report the mean, the median, the first and the third quartile of the posterior distribution of the elements of $\theta_{t}$ corresponding to selected lags and the direct cumulative impact of country specific and common monetary policy shocks, respectively. The overall shape of the posterior distributions of the elements of $\theta_{t}$ can be appreciated also from Figure 2, which plots the box-plot diagram of these distributions for each yearly subperiod considered from 1994 to $1998 .{ }^{17}$

\footnotetext{
${ }^{17} \mathrm{~A} \mathrm{Box}$ plot is a convenient graphical representations of the distribution of a variable which provides descriptive and diagnostic information. The box contains the central 50 percent of the distribution. The line inside the boox is the median, while the two top sides represent the first and the third quartile respectively. Consequently, the length of the box measures the dispersion of the distribution and the position of the line inside the box its degree of symmetry. Outliers, i.e., observations falling under the 1 percent tails of the distributions, have been dropped.
} 
Country specific monetary policy shocks appear to have had a system-wide effect peaking between 12 and 18 months in the mid-1990s. Toward the end of the 1990s, instead, the peak effect seems to occur earlier, between six and nine months. Similarly, the system-wide effects of common monetary policy shocks in 1997-98 seem to peak earlier than in 1994-95.

This evidence is consistent with what shown above and confirms that the European-wide transmission mechanism of monetary policy might have become shorter in the second part of the 1990s. Country specific shocks have a sizable negative cumulative effect, while common shocks have a generally smaller effect, possibly not significantly different from zero.

Even though they are not directly comparable with those reported by Tristani and Monticelli (1999, par. 6.3 and Figure 3), our results suggest that the European-wide effects of monetary policy may be less persistent than what suggested by their results. In their exercise, a temporary one standard deviation monetary policy shock becomes statistically insignificant only after 18-20 months, and its effects are quantitatively negligible within two years. We observe a similar pattern when the model is estimated without time-varying coefficients. But when the model is specified with time-varying coefficients this conclusion holds only for the beginning of the 1990s. In the second part of the 1990s, monetary policy seems to have affected economic activity with shorter lags.

\section{Conclusions}

In this paper we study empirically the transmission mechanism of monetary policy in four European countries using dynamic heterogenous models estimated in a Bayesian fashion with pre-EMU data.

Analyzing ERM data to understand what is happening under EMU has been done be fore, and will continue to be done for sometime. The econometric framework used in this paper shares several features with the 'ideal' one to run such an experiment: (i) the model's specification is the same across countries; (ii) no strong a priori restriction is imposed on the behavior of the central banks studied, letting the data reveal which were the relevant 
objectives in different stages of the run up to EMU; (iii) intra-European exchange rate movements as well as regional (real) interdependencies, through which monetary policy worked in part under ERM, are controlled for in assessing the impact of monetary policy on economic activity; and (iv) the effects of both country specific and common monetary policy shocks are analyzed, thereby controlling for the heterogeneity of central banks' preferences under EMS. Most importantly, however, the parameters of the reaction functions and those describing the transmission mechanism of monetary policy are allowed to change both across countries and time periods in our empirical framework. Therefore, our empirical results should be robust to the Lucas' critique and help understanding how differences in the transmission mechanism of European monetary policy evolved over time.

The empirical results presented show that there are differences in the timing of the effects of monetary policy across European countries, and that the degree of heterogeneity of the transmission mechanism has not decreased over time during the second half of the 1990s, even though the parameters of the transmission mechanism do seem to have changed over time. We have shown also that the European-wide effects of monetary policy take 6-7 months to appear, peak at 12-18, and disappear within 24 months. These results are consistent with what previously found in the literature in that they point to some degree of heterogeneity in the transmission mechanism of monetary policy. Unlike the results found in previous studies, however, they suggest that these cross-country differences are mainly with regards to the short term impact of monetary policy. As standard monetary theory suggests, we have given evidence suggesting that monetary policy might have become progressively more neutral in all countries considered in the long run.

This work can be extended in several directions. First, it would be desirable to extend the sample of countries analyzed to include all eleven members of EMU, and possibly also other European countries currently outside EMU. Second, it would be interesting to study the effect of monetary policy at regional rather than national level and to compare European countries (and/or regions) with American States. Finally, it would be useful to improve upon our definition of a common monetary policy shock and to attempt at framing the questions asked in this paper in a full blown panel VAR empirical framework. 


\section{A Estimation}

In this appendix we present details of the estimation procedures used in both stages of the empirical analysis. In both stages the estimation is Bayesian. Thus, given the specification of the systems of reaction functions and output equations discussed in the main text, prior distributions and initial conditions on the model's hyperparameters must be combined with the information contained in the data in the form of likelihood functions to produce posterior estimates of the parameters of interest. In both stages of the empirical analysis, it is not possible to obtain close-form solutions for the posterior distributions of interest, and hence we must rely on numerical integration. For the latter, we use the Gibbs sampling method, a widely used recursive Monte Carlo simulation method, (see e.g. Geman and Geman (1984), Gelfand and Smith (1990), Gelfand et al. (1990) among others).

\section{A.1 Reaction functions}

The probability density function (pdf) of the data for each block $j$ of (4), conditional on the exogenous variables in the model and on the initial observations on $R_{j t}$, is

$$
L\left(\delta_{j t}, \Sigma_{j j} \mid Z_{j t}\right) \propto\left|\Sigma_{j j}\right|^{-T / 2} \exp \left[-\frac{1}{2} \sum_{\delta}\left(R_{j t}-Z_{j t} \delta_{j t}\right)^{\prime} \Sigma_{j j}^{-1}\left(R_{j t}-Z_{j t} \delta_{j t}\right)\right] .
$$

The prior assumptions on the model's parameters generalize those introduced by Zellner (1971) to take into account the presence of time-varying coefficients: a time-varying, multivariate normal prior, i.e., a Minnesota-type of prior (Doan and others, 1984), for the regression parameters $\left(\delta_{j t}\right)$ is combined with a diffuse prior on the variance-covariance matrix of the residuals, $\Sigma_{j j}$. Thus, assuming prior independence:

$$
p\left(\delta_{j t}, \Sigma_{j j}\right)=p\left(\delta_{j y}\right) p\left(\Sigma_{j j}\right)
$$

with

$$
\begin{aligned}
p\left(\Sigma_{j j}\right) & \propto\left|\Sigma_{j j}\right|^{-\left(G_{j}+1\right) / 2} \\
\delta_{j t} & =P_{j} \delta_{j t-1}+\left(I-P_{j}\right) \bar{\delta}_{j}+\eta_{j t} \\
\eta_{j t} & \sim N\left(0, \Phi_{j}\right)
\end{aligned}
$$


where $P_{j}$ is a $G_{j} k_{j} \times G_{j} k_{j}$ matrix governing the law of motion of $\delta_{j t}, \bar{\delta}_{j}$ is the unconditional mean of $\delta_{j t}, \Phi_{j}$ governs the time variation of $\delta_{j t}$, and $\eta_{j t}$ is assumed to be independent from $v_{j t}$. The assumption of prior independence is needed for analytical tractability. ${ }^{18}$ Note also that giving a joint prior on $\left(\delta_{j t}, \Sigma_{j j}\right)$ is equivalent to considering a prior on $\left(\delta_{j t}, A(0)_{j j}\right)$ as proposed by Sims and Zha (1998) and Zha (1999) if the model is exactly identified, which is the case dealt with here: hence, $A(0)_{j j}$ can be recovered from $\Sigma_{j j}$ through the one-to-one mapping between these two matrices.

In order to run the Gibbs sampler, the conditional posterior distributions of $\Sigma_{j j}^{-1}$ and $\delta_{j t}$ must be obtained. Combining the likelihood (15) with (16), it is not difficult to see that the conditional posterior distribution of $\Sigma_{j j}^{-1}$ is a Wishart:

$$
\Sigma_{j j}^{-1} \mid\left\{\delta_{j t}\right\}_{t}, R_{j 0} \sim W\left(T, \sum_{t}\left[\left(R_{j t}-Z_{j t} \delta_{j t}\right)\left(R_{j t}-Z_{j t} \delta_{j t}\right)^{\prime}\right]^{-1}\right) .
$$

The joint conditional posterior distribution of $\delta_{j 0}, \delta_{j 1}, \ldots, \delta_{j T} \mid \Sigma_{j j}$ is obtained in two steps as shown by Chib and Greenberg (1995). First, we initialize $\left\{\delta_{j t}\right\}_{t}$ for each $t$ by Kalman filter and save the output:

$$
\begin{aligned}
& \hat{\delta}_{j t \mid t}=\hat{\delta}_{j t \mid t-1}+\hat{-}_{j t \mid t-1} Z_{j t}^{\prime} F\left(R_{j t}-Z_{j t} \hat{\delta}_{j t \mid t-1}\right) \\
& \hat{-}_{j t \mid t}=\hat{-}_{j t \mid t-1}-\hat{-}_{j t \mid t-1} Z_{j t}^{\prime} F Z_{j t^{*}}{ }^{j}{ }_{t \mid i-1} \\
& F=\left(Z_{j t}{ }^{\prime} j \mid t-1, Z_{j t}^{\prime}+\Sigma_{j j}\right)^{-1} \\
& M_{t}=\hat{-} j t \mid t^{-}-1
\end{aligned}
$$

where $\hat{\delta}_{j t \mid t-1}=P_{j} \hat{\delta}_{j t-1 \mid t-1}+\left(I-P_{j}\right) \bar{\delta}_{j}$ and $\hat{-}_{j t \mid t-1}=P_{j^{-}}{ }_{j t-1 \mid t-1} P_{j}^{\prime}+\Phi_{j}$. Second, the joint conditional posterior distribution $\delta_{j 0}, \delta_{j 1}, \ldots, \delta_{j T} \mid \Sigma_{j j}$ is sampled in reverse time order from

$$
\begin{aligned}
\delta_{j T} \sim N\left(\hat{\boldsymbol{\delta}}_{j T \mid T}, \hat{-}_{j T \mid T}\right) \\
\delta_{j T-1} \sim N\left(\hat{\boldsymbol{\delta}}_{j T-1}, \hat{-}_{j T-1}\right) \\
\vdots \\
\delta_{j 0} \sim N\left(\hat{\boldsymbol{\delta}}_{\left.j 0,-\hat{j}_{j 0}\right)}\right.
\end{aligned}
$$

\footnotetext{
${ }^{18}$ See Leamer (1978, p.80) for a better justification of prior independence.
} 
where $\hat{\delta}_{j t}=\hat{\delta}_{j t \mid t}+M_{t}\left(\delta_{j t+1}-\hat{\delta}_{j t \mid t}\right)$, and $\hat{-}_{j t}=\hat{-}_{j t \mid t}-M_{t}{ }^{\prime}{ }_{j t+1 \mid t} M_{t}^{\prime}$.

To make the updating scheme described in (18)-(20) operational, initial values for $P_{j}$, $\Phi_{j},{ }_{j 0}$, and the vector $\hat{\delta}_{j 0}$, at time $t=1$ (the first period of the sample), must be assigned. Following Litterman $(1980,1986)$, we define the matrices $P_{j}, \Phi_{j}, \hat{-}_{j 0}, \hat{\delta}_{j 0}$ in terms of a few hyperparameters. These hyperparameters are assumed known and are estimated before starting the Gibbs sampler. More specifically, each $k_{j} \times 1$ vector $\delta_{j g 0}$ is assumed to depend only on one hyperparameter such that $\delta_{j g}^{0}=\left(0, \ldots, 0, \pi_{1, g}, 0, \ldots 0\right)_{j}$, where $\pi_{1, g}$ represents the prior mean of the coefficient of the lagged dependent variable in equation $g$ of block $j$. The individual components of $\hat{\delta}_{j 0}$ are assumed to be mutually independent and independent from analogous components in other equations of the block $j$; thereby, rendering the covariance matrix $-{ }_{j 0}$ diagonal. The diagonal elements of ${ }^{-}{ }_{j 0}$ are then defined so that, for each block $j$, the relative tightness of the prior of the coefficient of the lagged dependent variable, of other lagged endogenous variables, and of deterministic and exogenous variables is controlled by $\pi_{2, g}, \pi_{3, g}, \pi_{4, g}$, respectively. In practice, the prior variances of the parameters in equation $g$ of block $j$ are specified as follows:

$$
\operatorname{Var}\left(\delta_{j g}^{0}\right)= \begin{cases}\frac{\pi_{2, q}}{l} & \text { for lagged dependent variables } \\ \frac{\pi_{2, q} \pi_{3, q}}{l} \frac{\sigma_{g}}{\sigma_{i}} & \text { for other lagged endogenous variables } \\ \pi_{2,9} \pi_{4} \sigma_{g} & \text { for exogenous and deterministic variables }\end{cases}
$$

where $l$ denotes the lag length, and $\sigma_{g}$ is a scaling factor which takes into account the range of variation of different variables. ${ }^{19}$ Hence, the overall tightness in the system (the overall degree of uncertainty with which prior information is introduced in the model's specification) is controlled by $\pi_{2}$; and if $\pi_{2}$ goes to infinity, the prior becomes diffuse. The tightness of the coefficients of the lagged dependent variable relative to that of other lagged endogenous variables in the equation is controlled by $\pi_{3}$; if $\pi_{3}=0$, the prior defines a set of univariate autoregressive processes of order $\mathrm{p}$. Finally, $\pi_{4}$ controls the degree of uncertainty with respect to the coefficients of exogenous and deterministic variables.

The time variation introduced in the model's parameters a priori is governed by the

\footnotetext{
${ }^{19}$ This scaling factor is usually estimated from a set of univariate $A R(m)$ models for each variable.
} 
matrices $P_{j}$ and $\Phi_{j}$. These matrices are defined as:

$$
\begin{gathered}
P_{j}=\operatorname{diag}\left(P_{j 1}, \ldots P_{j G_{j}}\right) \\
\Phi_{j}=\operatorname{diag}\left(\Phi_{j 1}, \ldots, \Phi_{j G_{j}}\right) \div j 0
\end{gathered}
$$

where $P_{j g}=\operatorname{diag}\left(\pi_{5, g}\right)$ are $k_{j} \times k_{j}$ matrices with $\pi_{5, g}$ controlling the coefficients of the law of motion of each $\delta_{j g}$, and $\Phi_{j g}=\operatorname{diag}\left(\pi_{6, g}\right)$ are $k_{j} \times k_{j}$ matrices with $\pi_{6, g}$ controlling the amount of time variation actually introduced in the model. Thus, a time-invariant model could be obtained by setting $\pi_{5}=1$ and $\pi_{6}=0$.

In sum, we have six hyperparameters for each equation of block $j$. The hyperparameters are estimated before running the Gibbs sampler by maximizing, equation-by-equation, the sample likelihood of the model written as a function of these hyperparameters themselves, while the model's parameters $\left(\delta_{j t}, \Sigma_{j j}\right)$ are initialized with a classical SUR estimate of the entire model. ${ }^{20}$ Then, the updating scheme (19) is run and the Gibbs sampler implemented, switching between (18) and (20) as if $\pi_{1}, \ldots, \pi_{6}$ were known. The Gibbs sampler runs 5000 times yielding 4000 draws from the posterior distributions after discarding the first 1000 draws.

\section{A.2 Output equations}

\section{A.2.1 Time variation}

Let $y_{i, \tau}^{s}$ denote annual output growth $\left(\ln \left(Y_{i \tau}^{s} / Y_{i \tau-1}^{s}\right)\right)$ at the $s$-th month of the $\tau$-th year for country $i$. For each country $i, y_{i, r}^{s}$ is modelled as follows:

$$
\begin{aligned}
y_{i \tau}^{s} & =X_{i \tau}^{s \prime} \beta_{i \tau}+\varepsilon_{i \tau}^{s} \\
i & =1, \ldots, G ; \quad \tau=1, \ldots, T_{1} ; \quad s=1, \ldots, S .
\end{aligned}
$$

In our sample, the number of years $\left(T_{1}\right)$ is 6 , the number of countries or endogenous variables $(G)$ is 4 , the number of subperiods for each year $(S)$ is 12 , and hence the total number of observations for each variable is $T=T_{1} * S=72$.

\footnotetext{
${ }^{20}$ Note that the first block of the model contains only one equation. In this case (18) becomes an inverted gamma and the equation's parameters can be initialized by OLS. All estimated hyperparameters are reported in Table 1.
} 
As noted in the main text, this system can be rewritten as:

$$
\begin{aligned}
y_{\tau}^{s}=X_{\tau}^{s} \beta_{\tau}+\varepsilon_{\tau}^{s}, & \varepsilon_{\tau}^{s} \sim N_{g}(0,-), \\
\beta_{\tau}=M_{o} \theta_{\tau}+\zeta_{\tau}, & \zeta_{\tau} \sim N_{s}\left(0, B_{o, t}\right), \\
\theta_{\tau}=\theta_{\tau-1}+\eta_{\tau}, & \eta_{\tau} \sim N_{m}\left(0, B_{1}\right) .
\end{aligned}
$$

The likelihood of the data is:

$$
\propto|-|^{-T / 2} \exp \left\{-\frac{1}{2} \sum_{\tau} \sum_{\delta}\left(y_{\tau}^{s}-X_{\tau}^{s} \beta_{\tau}\right)^{\prime}-{ }^{-1}\left(y_{\tau}^{s}-X_{\tau}^{s} \beta_{\tau}\right)\right\} .
$$

The prior information is completed by assuming:

$$
\begin{aligned}
-^{-1} & \sim W\left(\omega_{o}, \Theta\right), \\
M_{0} & =e_{g}{ }^{\nwarrow} \backslash I_{k}, \\
B_{o, \tau} & =I_{g} \backslash \Sigma \forall \tau, \quad \Sigma^{-1} \sim W\left(\sigma_{o}, \Psi_{o}\right), \\
B_{1} & =\operatorname{diag}\left(\phi_{1} I_{k_{1}}, \phi_{2} I_{k-k_{1}}\right),
\end{aligned}
$$

where $e_{g}$ is a vector of ones of dimension $g \times 1, W\left(\omega_{0}, \theta\right)$ denotes a Wishart distribution with $\omega_{0}$ degrees of freedom and scale matrix $\theta, I_{j}$ denotes an identity matrix of dimension $j$, and $k_{1}$ is the number of monetary policy parameters. The time variation of the monetary policy parameters is controlled by $\phi_{1}$, while $\phi_{2}$ tightens the time variation of other parameters.

We set a diffuse prior on $\phi_{2}$ and we assume that the prior distribution of $\phi_{1}$ is an inverted gamma, $\phi_{1} \sim I G\left(\kappa_{0} / 2, \xi_{0} / 2\right)$. All hyperparameters of the system $\left(\omega_{0}, \Theta, \sigma_{o}, \Psi_{o}, \kappa_{0}, \xi_{0}\right)$ are assumed known.

The posterior densities of the parameters of interest are obtained by combining the likelihood of the data with the prior distributions above in the form of conditional posterior distributions as before. Letting $Y_{T}=\left(y_{1}, \ldots, y_{T}\right)$ denote the sample data and $\psi=$ $\left(\left\{\beta_{\tau}\right\}_{\tau},-,\left\{\theta_{\tau}\right\}_{\tau}, \Sigma, \phi_{1}, \phi_{2}\right)$ denote the parameters whose joint distribution needs to be found, we have:

$$
\begin{gathered}
\beta_{\tau} \mid Y_{T}, \psi_{-\beta_{\tau}} \sim N\left(\tilde{\beta}_{\tau}, V_{\tau}\right), \quad \tau \leq T_{1} \\
-{ }^{-1} \mid Y_{T}, \psi_{--} \sim W\left(\omega_{0}+T, \Theta_{T}\right)
\end{gathered}
$$




$$
\begin{gathered}
\Sigma^{-1} \mid Y_{T}, \psi_{-\Sigma} \sim W\left(\sigma_{o}+T_{1} g, \Psi_{T_{2}}\right) \\
\phi_{1} \mid Y_{T}, \psi_{-\phi_{1}} \sim I G\left(\frac{\left(v_{o}+T_{1} k_{1}\right)}{2}, \frac{\zeta_{o}+\sum_{\tau}\left(\theta_{\tau}^{1}-\theta_{t-1}^{1}\right)^{\prime}\left(\theta_{\tau}^{1}-\theta_{t-1}^{1}\right)}{2}\right) ; \\
\phi_{2} \mid Y_{T}, \psi_{-\phi_{2}} \sim I G\left(\frac{T_{1}\left(k-k_{1}\right)}{2}, \frac{\sum_{\tau}\left(\theta_{\tau}^{2}-\theta_{t-1}^{2}\right)^{\prime}\left(\theta_{\tau}^{2}-\theta_{t-1}^{2}\right)}{2}\right) ;
\end{gathered}
$$

where

$$
\begin{gathered}
\hat{\beta}_{\tau}=V_{\tau}\left(B_{o}^{-1} M_{o} \theta_{\tau}+\sum_{s} X_{\tau}^{s \prime}-{ }^{-1} y_{\tau}^{o}\right), \\
V_{T}=\left(B_{o}^{-1}+\sum_{s} X_{\tau}^{s \prime}-{ }^{-1} X_{\tau}^{s}\right)^{-1}, \\
\Theta_{T}=\left[\Theta^{-1}+\sum_{\tau} \sum_{s}\left(y_{\tau}^{s}-X_{\tau}^{s} \beta_{\tau}\right)\left(y_{\tau}^{s}-X_{\tau}^{s} \beta_{\tau}\right)^{\prime}\right]^{-1}, \\
\Psi_{T_{1}}=\left[\Psi_{o}^{-1}+\sum_{\tau} \sum_{s}\left(\beta_{i \tau}-\theta_{\tau}\right)\left(\beta_{i \tau}-\theta_{\tau}\right)^{\prime}\right]^{-1},
\end{gathered}
$$

with $\psi_{-\gamma}$ denoting $\psi$ without the parameter $\gamma$, and $\theta_{+}^{1}$ and $\theta_{+}^{2}$ denoting monetary policy parameters and other parameters, respectively.

The posterior distribution of $\left\{\theta_{\tau}\right\}_{\tau=0}^{T_{1}}$, conditional on the other parameters, is obtained using an updating scheme as in (20) above.

As for the hyperparameters, we set $\omega_{o}=g+1, \sigma_{o}=k+1$, and $\Psi_{o}=\operatorname{diag}(1.0)$, while $\theta$ is initialized with the variance-covariance matrix of a classical SUR estimation of (8). The parameters of the gamma distribution of $\phi_{1}$ are $\kappa_{o}=6$ and $\xi_{o}=1$, implying that the prior mean and the standard deviation of $\phi_{1}$ are 0.25 and 0.25 , respectively. To initialize the Gibbs sampler we set also $\phi_{1}=\phi_{2}=0.5,-=I_{g}$, and $\Sigma=I_{k}$, while all $\beta_{\tau}$ 's are initialized with the posterior mean obtained estimating the model without time-variation.

With these starting values the Gibbs sampler begins generating $\left\{\theta_{\tau}\right\}_{\tau=0}^{T_{1}}$ and then all the other parameters. The Gibbs sampler runs 5000 times yielding 4000 draws from the posterior distribution after discarding the first 1000 draws as before. 


\section{A.2.2 Time invariant model}

The model is also estimated restricting the coefficients to be constant over time. In this case, we used the following hierarchy

$$
\begin{aligned}
y_{t} & =X_{t} \beta+\varepsilon_{t}, & & \varepsilon_{t} \sim N_{g}(0,-) \\
\beta & =M_{o} \theta+\zeta, & & \zeta \sim N_{s}\left(0, B_{o}\right) \\
\theta & =M_{1} \mu+\eta_{t}, & & \eta \sim N_{m}\left(0, B_{1}\right)
\end{aligned}
$$

where now $t=1, \ldots, T$.

The likelihood now becomes:

$$
\propto|-|^{-T / 2} \exp \left\{-\frac{1}{2} \sum_{t=1}^{T}\left(y_{t}-X_{t} \beta\right)^{\prime}-{ }^{-1}\left(y_{t}-X_{t} \beta\right)\right\} .
$$

All the hyperparameters, including $\mu$ and $B_{1}$, are assumed to be known as before. In particular, we set $B_{1}^{-1}=0$, i.e., the third stage of the hierarchy is degenerate.

Using the same notation and priors as before, the conditional posterior distributions now are:

$$
\begin{gathered}
\beta \mid Y_{T}, \psi_{-\beta} \sim N\left(\hat{\beta}, V_{T}\right) ; \\
-^{-1} \mid Y_{T}, \psi_{--} \sim W\left(\omega_{o}+T, R_{T}\right) ; \\
\theta \mid Y_{T}, \psi_{-\theta} \sim N\left(\Delta_{1}\left(B_{1}^{-1} M_{1} \mu+M_{o}^{\prime} B_{o}^{-1} \beta\right), \Delta_{1}\right) ; \\
\Sigma^{-1} \mid Y_{T}, \psi_{-\Sigma} \sim W\left(\sigma_{o}+g, \Psi_{g}\right) ;
\end{gathered}
$$

where

$$
\begin{gathered}
\hat{\beta}=V_{T}\left(B_{0}^{-1} M_{0} \theta+\sum_{t} X_{t^{-}}^{\prime}{ }^{-1} y_{t}\right), \quad V_{T}=\left(B_{o}^{-1}+\sum_{t} X_{t^{-}}^{\prime}{ }^{-1} X_{t}\right)^{-1}, \\
R_{T}=\left[R_{0}^{-1}+\sum_{t=1}^{T}\left(y_{t}-X_{t} \beta\right)\left(y_{t}-X_{t} \beta\right)^{\prime}\right]^{-1}, \\
\Delta_{1}=\left(B_{1}^{-1}+M_{o}^{\prime} B_{o}^{-1} M_{0}\right)^{-1}, \\
\Psi_{g}=\left[\Psi_{0}^{-1}+\sum_{i=1}^{g}\left(\beta_{i}-\theta\right)\left(\beta_{i}-\theta\right)^{\prime}\right]^{-1} .
\end{gathered}
$$

Finally, the Gibbs sampler is initialized as done in the case of the time-varying model. 


\section{B Data}

All the data used are from the International Financial Statistics (IFS) database of the IMF, except daily exchange rates which were provided by Marcello Pericoli of the Bank of Italy. The basic dataset is composed of monthly observations from 1985:01 to 1998:12 for the following series:

1. Consumer price index, IFS line $64(C P I)$;

2. Industrial production index, IFS line $66(I P)$;

3. Nominal exchange rate vis-a-vis the U.S. dollar (period average), IFS line rf ( $N E R$ );

4. Interest rates (Theasury Bill rate), IFS line 60c (IR);

5. Daily nominal exchange rate, Bank of Italy (DNER).

The following transformations of the basic data have been used:

6. $\pi_{i, t}=\log \left(C P I_{t} / C P I_{t-12}\right)$;

7. $y_{i, t}=\log \left(I P_{t}\right)$;

8. $R_{i, t}=\log \left(1+I R_{t} / 100\right)$;

9. $y_{i, t}=\log \left(I P_{t} / I P_{t-12}\right)$;

10. $\sigma_{i, t}=\operatorname{stdev}\left[\log \left(D N E R_{s} / D N E R_{s}^{*}\right)\right]$,

where stdev denotes the intra-month standard deviation, and $D N E R$; is an HP filtered trend with smoothing parameter equal to 1600 . Infiation, output, and exchange rate gaps-in the text denoted respectively $\left(\pi_{i, t}-\pi_{i}^{*}\right),\left(y_{i, t}-y_{i}^{*}\right)$, and $\left(e_{i t}-e_{i}^{*}\right)$-were computed as $\log \left(\left(C P I_{\mathrm{t}} / C P I_{t-12}\right) /\left(C P I_{t} / C P I_{t-12}\right)^{*}\right), \log \left(I P_{t} / I P^{*}\right)$, and $\log \left(N E R_{t} / N E R^{*}\right)$, respectively, where $\left(C P I_{t} / C P I_{t-12}\right)^{*}, I P^{*}$, and $N E R^{*}$ denote the deterministic components of a linear regression of $\left(C P I_{t} / C P I_{t-12}\right), I P_{t}$, and $N E R_{t}$ on a constant and a linear trend, a constant and a quadratic trend, and a simple constant, respectively. 
Tables

Table 1. Estimated hyperparameters in the reaction functions

\begin{tabular}{|c|cccccc|c|}
\hline & $\pi 1$ & $\pi 2$ & $\pi 3$ & $\pi 4$ & $\delta$ & $\pi 6$ & Likelihood \\
\cline { 2 - 8 } GER & 0,97582 & 0,02343 & 0,18227 & 13804,4 & 0,99887 & $7,7245 E-09$ & 1025,122 \\
FRN & 0,08534 & 0,72456 & 0,02525 & $1,46355 E-05$ & 0,99979 & $1,12253 E-08$ & 953,881 \\
IIL & 0,05922 & 0,05099 & 0,34916 & 171320,008 & 1 & $9,62304 E-09$ & 665,236 \\
SPN & 0,01891 & 0,17227 & 0,00872 & 5878,8848 & 1 & $1,3967 E-08$ & 856,82 \\
\hline
\end{tabular}

Notes:

$\pi 1=$ Prior mean on first lag

$x=$ Overall tightress

$x_{3}=$ Relative tightness on other variables

$\pi A=$ Reiative tightness on the constant

$\pi S=$ Law of motion of the parameter

$\times 6=$ Relative tightness on time variation 
Table 2. Estimated impact of idiosyncratic monetary policy shocks. Several lags. All countries

\begin{tabular}{|c|c|c|c|c|c|}
\hline & & GER & FRN & ITL & SPN \\
\hline \multirow[t]{4}{*}{$\operatorname{lag} 6$} & 1stQu. & $-0,1728$ & $-0,0402$ & $-0,0723$ & $-0,0673$ \\
\hline & Mean & $-0,0554$ & 0,0638 & 0,0522 & 0,0391 \\
\hline & Median & $-0,0576$ & 0,0623 & 0,0489 & 0,0314 \\
\hline & 3rd Qu. & 0,0603 & 0,1644 & 0,1666 & 0,1448 \\
\hline \multirow[t]{4}{*}{$\operatorname{lag} 12$} & 1st Qu. & 0,0627 & $-0,0427$ & 0,1033 & 0,0868 \\
\hline & Mean & 0,1659 & 0,0570 & 0,2162 & 0,1831 \\
\hline & Median & 0,1656 & 0,0571 & 0,2160 & 0,1855 \\
\hline & 3rdQu. & 0,2702 & 0,1592 & 0,3279 & 0,2807 \\
\hline \multirow[t]{4}{*}{$\operatorname{lag} 14$} & 1stQu. & $-0,1770$ & $-0,1048$ & $-0,1519$ & $-0,0453$ \\
\hline & Mean & $-0,0699$ & $-0,0084$ & $-0,0405$ & 0,0558 \\
\hline & Median & $-0,0687$ & $-0,0045$ & $.0,0360$ & 0,0576 \\
\hline & 3rd Qu. & 0,0406 & 0,0928 & 0,0741 & 0,1591 \\
\hline \multirow[t]{4}{*}{$\operatorname{lag} 16$} & 1st Qu. & $-0,2567$ & $-0,1734$ & $-0,2973$ & $-0,2636$ \\
\hline & Mean & $.0,1465$ & $-0,0667$ & $-0,1674$ & $-0,1631$ \\
\hline & Median & $-0,1476$ & $-0,0705$ & $-0,1848$ & $-0,1668$ \\
\hline & 3ıdQu. & $-0,0330$ & 0,0386 & $-0,0776$ & $-0,0626$ \\
\hline \multirow[t]{4}{*}{$\operatorname{lag} 18$} & 1stQu. & $-0,3311$ & $-0,2140$ & $-0,3798$ & $\cdot 0,2961$ \\
\hline & Mean & $-0,2203$ & $-0,1156$ & $-0,2639$ & $-0,1963$ \\
\hline & Median & $-0,2225$ & $-0,1166$ & $.0,2622$ & $-0,1977$ \\
\hline & 3ıd Qu. & $-0,1106$ & $-0,0189$ & $-0,1431$ & $-0,0998$ \\
\hline \multirow[t]{4}{*}{$\operatorname{lag} 24$} & 1st Qu. & $-0,2455$ & $-0,1391$ & $-0,2892$ & $-0,2235$ \\
\hline & Mean & $-0,1391$ & $-0,0451$ & $.0,1738$ & $-0,1269$ \\
\hline & Median & $-0,1369$ & $-0,0483$ & $-0,1746$ & 0,1273 \\
\hline & 3rdQu. & $-0,0336$ & 0,0471 & $-0,0557$ & $-0,0324$ \\
\hline \multirow[t]{4}{*}{ cumul 12} & 1st Qu. & $-0,6818$ & $-0,8361$ & $-0,7235$ & $-0,5365$ \\
\hline & Mean & $-0,4093$ & $-0,3678$ & $-0,2561$ & $\cdot 0,1521$ \\
\hline & Median & $.0,4156$ & $-0,3660$ & $-0,2678$ & $-0,1537$ \\
\hline & 3rd Qu. & 0,0764 & 0,1075 & 0,2019 & 0,2450 \\
\hline \multirow[t]{4}{*}{ cumul 24} & 1st Qu. & $-2,1080$ & $-2,0268$ & $-2,1834$ & $-1,3751$ \\
\hline & Mean & $-1,4115$ & $\cdot 1,3507$ & $-1,5098$ & $-0,8963$ \\
\hline & Median & $-1,4005$ & $-1,3469$ & $-1,5030$ & $-0,8947$ \\
\hline & $3 r d Q u$. & $-0,7002$ & $-0,6364$ & $-0,8351$ & $-0,3942$ \\
\hline
\end{tabular}

Note: For each lag the first quartile, the mean, the median, and the third quartile are reported 
Table 3. Testing the null: $F(q)=F(q 1)$. Idiosyncratic shocks

\begin{tabular}{|c|ccccc|}
\hline & all lags & lag 12 & lag 24 & cumul 12 & cumul 24 \\
\hline \hline \multirow{4}{*}{ joint } & 0.5020 & 0.1843 & 0.1385 & 0.0788 & 0.1530 \\
& $(0.0000)$ & $(0.0000)$ & $(0.0000)$ & $(0.0001)$ & $(0.0000)$ \\
Gervs Fm & 0.3370 & 0.1223 & 0.1008 & 0.0152 & 0.0138 \\
& $(0.0000)$ & $(0.0000)$ & $(0.0000)$ & $(0.7280)$ & $(0.8327)$ \\
Gervs Itt & 0.2528 & 0.0342 & 0.0285 & 0.0370 & 0.0172 \\
& $(0.0000)$ & $(0.0175)$ & $(0.0745)$ & $(0.0079)$ & $(0.5781)$ \\
& & & & & \\
Gervs Spn & 0.3058 & 0.0207 & 0.0095 & 0.0600 & 0.1045 \\
& $(0.0000)$ & $(0.3452)$ & $(0.9920)$ & $(0.0000)$ & $(0.0000)$ \\
Fm v sIt & 0.3223 & 0.2068 & 0.1658 & 0.0192 & 0.0198 \\
& $(0.0000)$ & $(0.0000)$ & $(0.0000)$ & $(0.4372)$ & $(0.4051)$ \\
& & & & & \\
Fm vs Spn & 0.3162 & 0.1675 & 0.0807 & 0.0767 & 0.1135 \\
& $(0.0000)$ & $(0.0000)$ & $(0.0000)$ & $(0.0000)$ & $(0.0000)$ \\
& & & & & \\
It vs Spn & 0.2388 & 0.033 & 0.0420 & 0.0342 & 0.1700 \\
& $(0.0000)$ & $(0.0245)$ & $(0.0016)$ & $(0.0175)$ & $(0.0000)$ \\
\hline
\end{tabular}

Note: numbers represent the Kolmogorov-Smimov statistics.

P.values in brackets. 
Table 4. Impact of a common monetary policy shock

(Selected lags; all countries)

\begin{tabular}{|c|c|c|c|c|c|}
\hline & & GER & FRN & ITL & SPN \\
\hline \multirow[t]{4}{*}{$\log 6$} & 1st Qu. & $-0,1859$ & $-0,2111$ & $-0,2111$ & $-0,2266$ \\
\hline & Mean & $-0,0352$ & $-0,0876$ & $\cdot 0,0627$ & $-0,1004$ \\
\hline & Median & $-0,0361$ & $-0,0847$ & $-0,0621$ & $-0,0987$ \\
\hline & 3id Qu. & 0,1031 & 0,0447 & 0,0893 & 0,0364 \\
\hline \multirow[t]{4}{*}{$\operatorname{lag} 12$} & 1st Qu. & $-0,0948$ & $-0,1071$ & $-0,0110$ & $-0,0309$ \\
\hline & Mean & 0,0240 & 0,0022 & 0,1196 & 0,0879 \\
\hline & Median & 0,0279 & 0,0027 & 0,1226 & 0,0917 \\
\hline & 3ıd Qu. & 0,1442 & 0.1105 & 0,2484 & 0.2017 \\
\hline \multirow[t]{4}{*}{$\operatorname{lag} 14$} & IstQu. & $-0,1516$ & $-0,1534$ & $-0,1812$ & $-0,0352$ \\
\hline & Mean & $-0,0234$ & $-0,0369$ & $-0,0401$ & 0,0860 \\
\hline & Median & $-0,0233$ & $-0,0335$ & $-0,0374$ & 0,0813 \\
\hline & 3rdQu. & 0,1092 & 0,0819 & 0,1013 & 0,2119 \\
\hline \multirow[t]{4}{*}{ lag 16} & Ist Qu. & $-0,3754$ & $-0,2446$ & $-0,2689$ & $-0,4232$ \\
\hline & Mean & $-0,2336$ & .0,1230 & $-0,1204$ & $-0,2953$ \\
\hline & Median & $-0,2328$ & $-0,1263$ & $-0,1190$ & $-0,2941$ \\
\hline & 3idQu. & $-0,0947$ & 0,0007 & 0,0259 & $-0,1644$ \\
\hline \multirow[t]{4}{*}{$\operatorname{lag} 18$} & IstQu. & $-0,4266$ & $-0,3938$ & $-0,5101$ & $-0,3967$ \\
\hline & Mean & $-0,3063$ & $-0,2864$ & $-0,3803$ & $-0,2803$ \\
\hline & Median & $-0,3040$ & $-0,2831$ & $-0,3768$ & $\cdot 0,2742$ \\
\hline & $3 ı d Q u$. & $-0,1803$ & $-0,1739$ & $-0,2481$ & $-0,1633$ \\
\hline \multirow[t]{4}{*}{$\operatorname{lag} 24$} & IstQu. & 0,0330 & $-0,0961$ & $-0,1214$ & $-0,1179$ \\
\hline & Mean & 0,1530 & 0,0193 & 0,0161 & 0,0011 \\
\hline & Median & 0,1549 & 0,0176 & 0,0201 & 0,0027 \\
\hline & 3rd Qu. & 0,2779 & 0,1321 & 0,1584 & 0.1187 \\
\hline \multirow[t]{4}{*}{ cumul 12} & IstQu. & $-0,8175$ & $-0,6696$ & $-0,3923$ & $-0,8722$ \\
\hline & Mean & $-0,4686$ & $-0,3503$ & $-0,0138$ & $-0,5151$ \\
\hline & Median & $-0,4445$ & $-0,3420$ & $-0,0148$ & $-0,5067$ \\
\hline & 3rd Qu. & $-0,0920$ & $-0,0160$ & 0,3149 & $-0,1464$ \\
\hline \multirow[t]{4}{*}{ cumul 24} & 1stQu. & $-1,2557$ & $-1,2482$ & $-1,1558$ & $-1,8280$ \\
\hline & Mean & $-0,6641$ & $-0,6647$ & $-0,4765$ & $-1,2416$ \\
\hline & Median & $-0,6495$ & $-0,6682$ & $-0,4726$ & $-1,2253$ \\
\hline & 3rd Qu. & $-0,0471$ & $.0,0924$ & 0,1960 & -0.6380 \\
\hline
\end{tabular}

Note: For each lag the first quartile, the mean, the median, and the third quartile are reported 
Table 5. Testing the null: $F(q)=F(q 1)$. Common shock

\begin{tabular}{|c|c|c|c|c|c|}
\hline & all lags & $\operatorname{lag} 12$ & $\operatorname{lag} 24$ & cumul 12 & cumul 24 \\
\hline joint & $\begin{array}{c}0,5640 \\
(0.0000)\end{array}$ & $\begin{array}{c}0,1275 \\
(0.0000)\end{array}$ & $\begin{array}{c}0,1853 \\
(0.0000)\end{array}$ & $\begin{array}{c}0,1822 \\
(0.0000)\end{array}$ & $\begin{array}{c}0,1935 \\
(0.0000)\end{array}$ \\
\hline Gervs Fm & $\begin{array}{c}0,3615 \\
(0.0000)\end{array}$ & $\begin{array}{c}0,0222 \\
(0.2668)\end{array}$ & $\begin{array}{c}0,1795 \\
(0.0000)\end{array}$ & $\begin{array}{c}0,0268 \\
(0.1100)\end{array}$ & $\begin{array}{c}0,0268 \\
(0.1100)\end{array}$ \\
\hline Ger vslt & $\begin{array}{c}0,2965 \\
(0.0000)\end{array}$ & $\begin{array}{c}0,0833 \\
(0.0000)\end{array}$ & $\begin{array}{c}0,1648 \\
(0.0000)\end{array}$ & $\begin{array}{c}0,1728 \\
(0.0000)\end{array}$ & $\begin{array}{c}0,0370 \\
(0.0079)\end{array}$ \\
\hline Ger vsSpn & $\begin{array}{c}0,3095 \\
(0.0000)\end{array}$ & $\begin{array}{c}0,0707 \\
(0.0005)\end{array}$ & $\begin{array}{c}0,2150 \\
(0.0000)\end{array}$ & $\begin{array}{c}0,0212 \\
(0.3175)\end{array}$ & $\begin{array}{c}0,1442 \\
(0.0000)\end{array}$ \\
\hline Fm vs $|t|$ & $\begin{array}{c}0,2658 \\
(0.0000)\end{array}$ & $\begin{array}{c}0,1430 \\
(0.0000)\end{array}$ & $\begin{array}{c}0,0148 \\
(0.7644)\end{array}$ & $\begin{array}{c}0,1328 \\
(0.0000)\end{array}$ & $\begin{array}{c}0,0308 \\
(0.0436)\end{array}$ \\
\hline Fmvs Spn & $\begin{array}{c}0,4812 \\
(0.0000)\end{array}$ & $\begin{array}{c}0,1060 \\
(0.0000)\end{array}$ & $\begin{array}{c}0,0185 \\
(0.4881)\end{array}$ & $\begin{array}{c}0,0435 \\
(0.0010)\end{array}$ & $\begin{array}{c}0,1570 \\
(0.0000)\end{array}$ \\
\hline ItI vsSpn & $\begin{array}{c}0,3405 \\
(0.0000)\end{array}$ & $\begin{array}{c}0,0305 \\
(0.0464)\end{array}$ & $\begin{array}{c}0,0197 \\
(0.4951)\end{array}$ & $\begin{array}{c}0,2290 \\
(0.0000)\end{array}$ & $\begin{array}{c}0,2188 \\
(0.0000)\end{array}$ \\
\hline
\end{tabular}

Note: numbers represent the Kolmogorov-Smimov slatistics. P-values in brackets. 


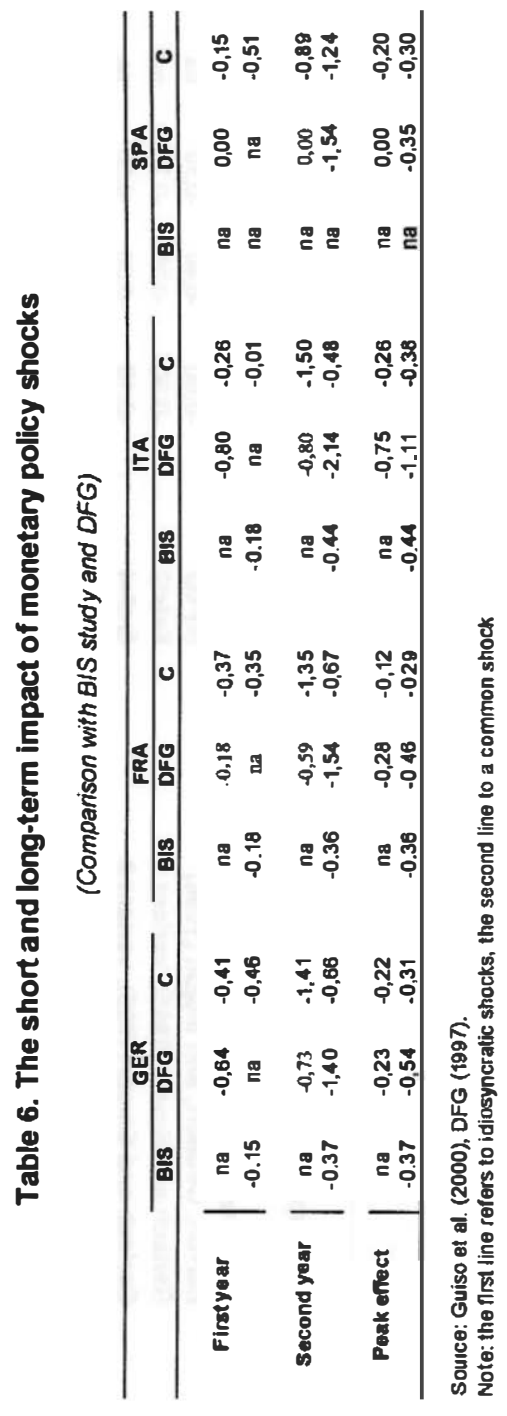




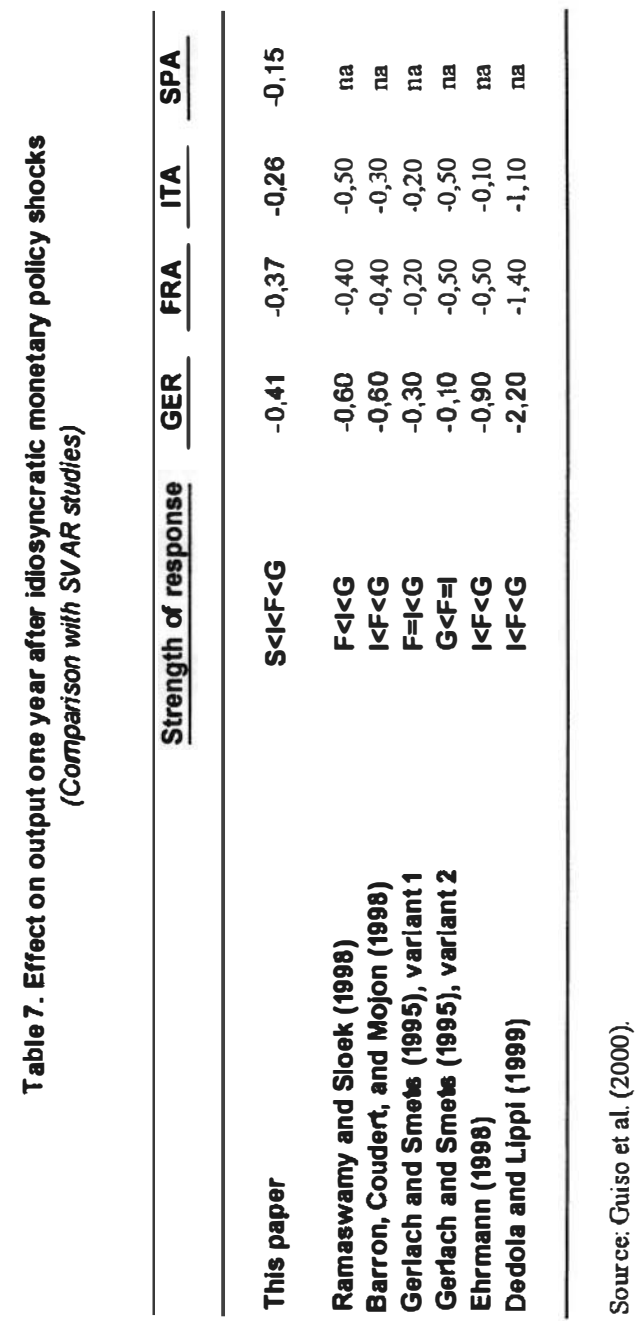


Table 8. Testing the null: $F(q)=F(q 1)$. Time varying model. Idiosyncratic shocks

all countries

\begin{tabular}{|c|c|c|c|c|c|}
\hline & 1994 & 1995 & 1996 & 1997 & 1998 \\
\hline all lags & $\begin{array}{c}0.3615 \\
(0.0000)\end{array}$ & $\begin{array}{c}0.3195 \\
(0.0000)\end{array}$ & $\begin{array}{c}0.3117 \\
(0.0000)\end{array}$ & $\begin{array}{c}0.3027 \\
(0.0000)\end{array}$ & $\begin{array}{c}0.2533 \\
(0.0000)\end{array}$ \\
\hline $\operatorname{lag} 12$ & $\begin{array}{c}0.0867 \\
(0.0012)\end{array}$ & $\begin{array}{c}0.0265 \\
(0.1161)\end{array}$ & $\begin{array}{c}0.0597 \\
(0.0000)\end{array}$ & $\begin{array}{c}0.0648 \\
(0.0000)\end{array}$ & $\begin{array}{c}0.039 \\
(0.0043)\end{array}$ \\
\hline lag 24 & $\begin{array}{c}0.0288 \\
(0.0704)\end{array}$ & $\begin{array}{c}0.107 \\
(0.0000)\end{array}$ & $\begin{array}{c}0.0495 \\
(0.0001)\end{array}$ & $\begin{array}{c}0.0445 \\
(0.0007)\end{array}$ & $\begin{array}{c}0.072 \\
(0.0000)\end{array}$ \\
\hline cumul 12 & $\begin{array}{c}0.0153 \\
(0.7280)\end{array}$ & $\begin{array}{c}0.019 \\
(0.4538)\end{array}$ & $\begin{array}{c}0.0158 \\
(0.6907)\end{array}$ & $\begin{array}{c}0.0543 \\
(0.0000)\end{array}$ & $\begin{array}{c}0.0215 \\
(0.3042)\end{array}$ \\
\hline cumul 24 & $\begin{array}{c}0.0158 \\
(0.6907)\end{array}$ & $\begin{array}{c}0.0155 \\
(0.7094)\end{array}$ & $\begin{array}{c}0.0183 \\
(0.5055)\end{array}$ & $\begin{array}{c}0.0268 \\
(0.1100)\end{array}$ & $\begin{array}{c}0.0112 \\
(0.9565)\end{array}$ \\
\hline
\end{tabular}

Note: numbers represent the Kolmogorov Smimov strtistics.

P-values in bracket. 
Table 9. Impect of Idiosyncr atlc monotory policy ahocks Soveral lage. All countries. All yeare

\begin{tabular}{|c|c|c|c|c|c|c|c|c|c|c|}
\hline & & & $\square 8$ & & & & & 12 & & \\
\hline & 1994 & 1995 & 1996 & 1997. & 1998 & 1994 & 1995 & 1996 & 1997 & 1998 \\
\hline OER & $\begin{array}{l}0,150 \\
0,001 \\
0,157\end{array}$ & $\begin{array}{l}0,170 \\
0,016 \\
0,138\end{array}$ & $\begin{array}{r}-0,175 \\
-0,02 \\
0,131\end{array}$ & $\begin{array}{r}-0,300 \\
-0,221 \\
-0,060\end{array}$ & $\begin{array}{l}-0,222 \\
-0,000 \\
0,160\end{array}$ & $\begin{array}{l}-0,386 \\
-0,292 \\
-0,040\end{array}$ & $\begin{array}{l}-0.325 \\
0,141 \\
0,019\end{array}$ & $\begin{array}{l}-0,347 \\
0,170 \\
-0,026\end{array}$ & $\begin{array}{l}0,180 \\
0,000 \\
0,162\end{array}$ & $\begin{array}{l}-0,262 \\
-0,067 \\
0,124\end{array}$ \\
\hline FNON & $\begin{array}{l}0.121 \\
0,043 \\
0,206\end{array}$ & $\begin{array}{l}0,210 \\
0,072 \\
0,073\end{array}$ & $\begin{array}{l}-0,123 \\
0,027 \\
0,169\end{array}$ & $\begin{array}{r}-0,306 \\
-0,229 \\
-0,081\end{array}$ & $\begin{array}{l}-0,196 \\
0.009 \\
0.200\end{array}$ & $\begin{array}{l}-0.456 \\
-0,218 \\
-0,128\end{array}$ & $\begin{array}{l}-0,300 \\
0,136 \\
0,025\end{array}$ & $\begin{array}{l}-0,306 \\
0,2006 \\
-0,067\end{array}$ & $\begin{array}{l}-0,257 \\
-0,088 \\
0,084\end{array}$ & $\begin{array}{l}0.237 \\
0.000 \\
0.144\end{array}$ \\
\hline$m$ & $\begin{array}{l}0.122 \\
0.049 \\
0.196\end{array}$ & $\begin{array}{l}0,201 \\
0,060 \\
0.106\end{array}$ & $\begin{array}{r}-0.178 \\
-0,011 \\
0.146\end{array}$ & $\begin{array}{l}-0,257 \\
-0,100 \\
-0,003\end{array}$ & $\begin{array}{l}-0.2003 \\
-0.006 \\
0.198\end{array}$ & $\begin{array}{r}-0,412 \\
-0,200 \\
-0,000\end{array}$ & $\begin{array}{l}-0.281 \\
-0.100 \\
0,063\end{array}$ & $\begin{array}{r}-0,300 \\
-0,124 \\
0,025\end{array}$ & $\begin{array}{l}-0.234 \\
-0,062 \\
0.122\end{array}$ & $\begin{array}{l}-0.203 \\
0.002 \\
0.886\end{array}$ \\
\hline SPN & $\begin{array}{l}-0,000 \\
0,060 \\
0,224\end{array}$ & $\begin{array}{l}-0.181 \\
-0.860 \\
0.112\end{array}$ & $\begin{array}{l}-0.280 \\
-0,062 \\
0.098\end{array}$ & $\begin{array}{l}-0.375 \\
-0.200 \\
-0.028\end{array}$ & $\begin{array}{l}-0.196 \\
0,000 \\
0.204\end{array}$ & $\begin{array}{l}-0,025 \\
-0,246 \\
0.074\end{array}$ & $\begin{array}{l}-0.286 \\
-0,113 \\
0.068\end{array}$ & $\begin{array}{l}0,313 \\
0,180 \\
.0,021\end{array}$ & $\begin{array}{l}-0,243 \\
0,074 \\
0,055\end{array}$ & $\begin{array}{l}-0,223 \\
0.2020 \\
0,164\end{array}$ \\
\hline
\end{tabular}

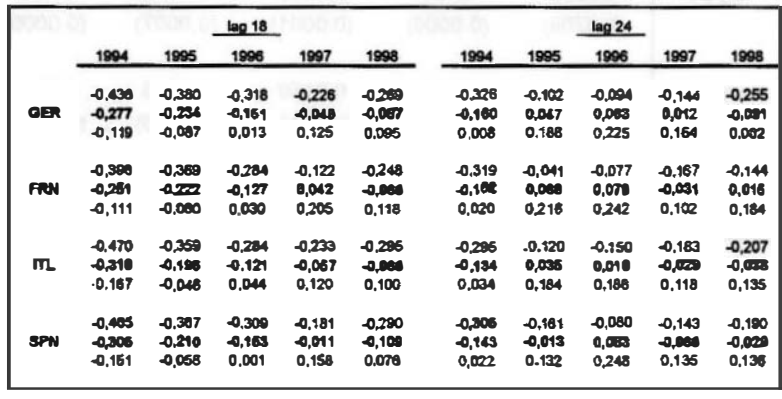

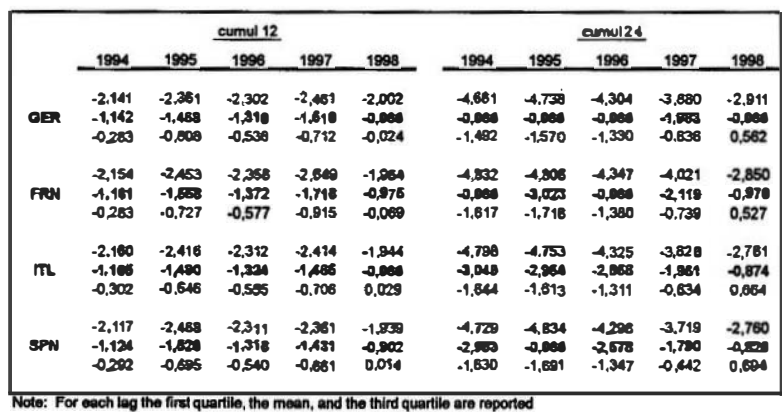


Table 10. Testing the null: $F(q)=F(q 1)$. Time varying model. Common shock

all countries

\begin{tabular}{|c|c|c|c|c|c|}
\hline & 1994 & 1995 & 1996 & 1997 & 1998 \\
\hline all lags & $\begin{array}{c}0.1515 \\
(0.0000)\end{array}$ & $\begin{array}{c}0.1535 \\
(0.0000)\end{array}$ & $\begin{array}{c}0.1318 \\
(0.0000)\end{array}$ & $\begin{array}{c}0.0822 \\
(0.0000)\end{array}$ & $\begin{array}{c}0.0702 \\
(0.0000)\end{array}$ \\
\hline Jag 12 & $\begin{array}{c}0.0115 \\
(0.9479)\end{array}$ & $\begin{array}{c}0.0118 \\
(0.9385)\end{array}$ & $\begin{array}{c}0.075 \\
(0.0000)\end{array}$ & $\begin{array}{r}0.0183 \\
(0.5055)\end{array}$ & $\begin{array}{r}0.0158 \\
(0.6907)\end{array}$ \\
\hline $\operatorname{lag} 24$ & $\begin{array}{r}0.0165 \\
(0.6342)\end{array}$ & $\begin{array}{c}0.0245 \\
(0.1749)\end{array}$ & $\begin{array}{c}0.0195 \\
(0.421)\end{array}$ & $\begin{array}{c}0.0433 \\
(0.0011)\end{array}$ & $\begin{array}{r}0.0227 \\
(0.2438)\end{array}$ \\
\hline cumul 12 & $\begin{array}{r}0.0175 \\
(0.5596)\end{array}$ & $\begin{array}{c}0.0172 \\
(0.5781)\end{array}$ & $\begin{array}{c}0.0068 \\
(1.0000)\end{array}$ & $\begin{array}{c}0.0175 \\
(0.5596)\end{array}$ & $\begin{array}{r}0.0088 \\
(0.9973)\end{array}$ \\
\hline cumul24 & $\begin{array}{c}0.0062 \\
(1.0000)\end{array}$ & $\begin{array}{c}0.0152 \\
(0.7280)\end{array}$ & $\begin{array}{c}0.0125 \\
(0.9048)\end{array}$ & $\begin{array}{c}0.0063 \\
(1.0000)\end{array}$ & $\begin{array}{c}0.01 \\
(0.9857)\end{array}$ \\
\hline
\end{tabular}

Note: numbers represent the Kolmogorov-Smimov statistics.

P-values in brackets. 
Table 11. Impact of a common monetary policy shock. Several lags. All countries. All years

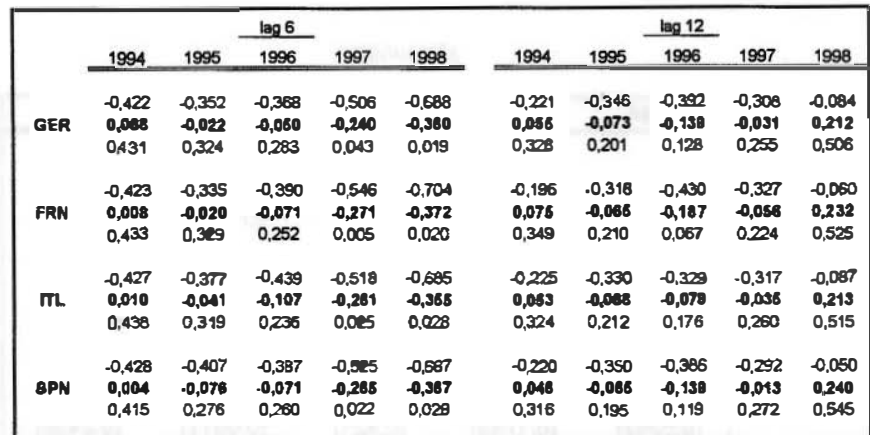

\begin{tabular}{|c|c|c|c|c|c|c|c|c|c|c|}
\hline & \multicolumn{5}{|c|}{ lag 18} & \multicolumn{5}{|c|}{$\log 24$} \\
\hline & 1994 & 1995 & 1996 & 1997 & 1998 & 1994 & 1995 & 1996 & 1997 & 1998 \\
\hline \multirow{3}{*}{ GER } & 0.718 & $-0,587$ & $-0,479$ & $-0,627$ & $-0,583$ & $-0,586$ & $-0,505$ & $-0,522$ & -0.532 & $-0,511$ \\
\hline & 0,480 & 0,286 & $\cdot 0,142$ & 0,277 & 0,201 & 0,275 & $-0,281$ & 0,266 & $-0,266$ & $-0,208$ \\
\hline & $-0,214$ & $-0,005$ & 0.154 & -0.046 & 0.068 & -0.008 & $-0,049$ & 0,001 & 0.014 & 0,100 \\
\hline \multirow{3}{*}{ FRN } & $-0,768$ & $-0,636$ & 0,488 & $-0,565$ & $-0,586$ & $-0,556$ & $-0,527$ & $-0,576$ & $-0,022$ & $-0,550$ \\
\hline & $-0,497$ & 0,336 & 0,152 & $-0,212$ & $-0,209$ & $-0,274$ & $.0,341$ & $-0,290$ & 0,301 & 0,246 \\
\hline & 0.250 & 0,078 & 0.150 & 0,022 & 0.034 & $-0,005$ & $-0,083$ & $.0,041$ & -0.075 & 0,00 \\
\hline \multirow{3}{*}{ IL } & -0.775 & $-0,593$ & $-0,482$ & $-0,583$ & $-0,581$ & -0.541 & $-0,494$ & -0.547 & $-0,587$ & $-0,550$ \\
\hline & $-0,504$ & $-0,297$ & $.0,140$ & 0,220 & 0,202 & 0,250 & 0,279 & 0,274 & 0,311 & 0.234 \\
\hline & $-0,250$ & 0,0028 & 0.147 & 0.012 & 0.024 & 0.024 & -0.046 & -0.017 & -0.043 & 0,080 \\
\hline \multirow{3}{*}{ 8PN } & -0.698 & $-0,583$ & -0.470 & $-0,573$ & $-0,554$ & $-0,551$ & $-0,543$ & $-0,527$ & .0 .551 & $-0,507$ \\
\hline & $-0,434$ & 0,262 & 0,138 & 0,218 & 0,173 & 0,262 & 0,315 & 0,258 & 0,277 & $.0,192$ \\
\hline & $\cdot 0,185$ & $-0,015$ & 0,164 & 0,021 & 0,064 & 0.009 & $-0,082$ & 0,004 & $-0,010$ & 0,110 \\
\hline
\end{tabular}

\begin{tabular}{|c|c|c|c|c|c|c|c|c|c|c|}
\hline & \multicolumn{5}{|c|}{ cumul 12} & \multicolumn{5}{|c|}{ cumul 24} \\
\hline & 1994 & 1995 & 1996 & 1997 & 1998 & 1994 & 1995 & 1996 & 1997 & 1998 \\
\hline \multirow{4}{*}{ GER } & $-0,805$ & $-0,842$ & $-1,332$ & -1.481 & $-1,725$ & $-2,343$ & $-2,456$ & $-2,447$ & $-2,244$ & $-1,980$ \\
\hline & OASE & 0,248 & $.0,183$ & $-0,606$ & OABB & 0,005 & $\cdot 1,151$ & $-0,094$ & 0,827 & 0,200 \\
\hline & 1,664 & 1,353 & 1,099 & 0,491 & 0,833 & 0.743 & 0.202 & 0,551 & 0,601 & 1,507 \\
\hline & $-0,781$ & $-0,760$ & $-1,307$ & -1.500 & -1.707 & $-2,330$ & $-2,460$ & $-2,006$ & $-2,297$ & -2000 \\
\hline \multirow[t]{3}{*}{ FRN } & 0,400 & 0,300 & 0,150 & 0,615 & 0,498 & 0,790 & $-1,120$ & 0,971 & $-0,887$ & 0,188 \\
\hline & 1,642 & 1,418 & 1,122 & 0,410 & 0,794 & 0,743 & 0.270 & 0,57 & 0,617 & 1.552 \\
\hline & $-0,731$ & $-0,805$ & $-1,402$ & $-1,505$ & $-1,668$ & $-2,330$ & $-2,450$ & $-2,406$ & $-2,297$ & $-2,000$ \\
\hline \multirow[t]{3}{*}{$m 2$} & 0,496 & 0,102 & $-0,203$ & 0,570 & OASA & 0,790 & $-1,120$ & $-0,071$ & 0,257 & 0,188 \\
\hline & 1,715 & 1,302 & 1,039 & 0.431 & 0,812 & 0.743 & 0.270 & $0,5 n$ & 0.617 & 1.50 \\
\hline & $-0.7 \notin 9$ & $-0,923$ & $-1,354$ & -1.454 & $-1,560$ & .2342 & .2572 & $-2,468$ & $-2,190$ & $.2,039$ \\
\hline \multirow[t]{2}{*}{ BPN } & 0,854 & 0,187 & 0,160 & OAB1 & 0,431 & 0,814 & $-1,286$ & $-1,004$ & $-0,796$ & 0,208 \\
\hline & $1, \infty 87$ & 1.328 & 1,075 & 0,498 & 0,843 & 0,691 & 0,251 & 0,538 & 0,682 & 1,557 \\
\hline
\end{tabular}

Note: For each lag the first quartile, the mean, and the third quartile are reported 
Table 12. Mean estimated impact of idlosyncratic monetery policy shocks. Several lags. All years

\begin{tabular}{|c|c|c|c|c|c|c|}
\hline & & 198 & 1998 & 1986 & 1997 & 1998 \\
\hline \multirow[t]{4}{*}{$\operatorname{lag} 1$} & IstQu. & $-0,226$ & $-0,175$ & $.0,080$ & $-0,256$ & $-0,510$ \\
\hline & Maen & $-0,065$ & $-0,048$ & 0,078 & $-0,080$ & $-0,324$ \\
\hline & Modian & $-0,069$ & $-0,043$ & 0,073 & $-0,091$ & $.0,344$ \\
\hline & JroQu. & 0,096 & 0,088 & 0.228 & 0,086 & $-0,143$ \\
\hline \multirow[t]{4}{*}{$\operatorname{lng} 6$} & 1stQu. & $-0,114$ & $-0,174$ & $-0,162$ & $.0,347$ & $-0,199$ \\
\hline & Moan & 0,034 & $-0,040$ & $-0,024$ & $-0,169$ & $-0,018$ \\
\hline & Modian & 0,029 & $-0,036$ & $-0,037$ & $-0,196$ & $-0,020$ \\
\hline & 3rd Qu. & 0,175 & 0,089 & 0,104 & $-0,036$ & 0,169 \\
\hline \multirow[t]{4}{*}{$\log 9$} & 1stQu. & $-0,460$ & $-0,553$ & $-0,409$ & $-0,615$ & $-0,420$ \\
\hline & Maen & $-0,295$ & $-0,410$ & $-0,251$ & $-0,457$ & $-0,236$ \\
\hline & Mecfan & $-0,306$ & $-0,412$ & $-0,252$ & $-0,447$ & $-0,232$ \\
\hline & 3ndQu. & $-0,143$ & -0.264 & $.0,101$ & $-0,296$ & $-0,052$ \\
\hline \multirow[t]{4}{*}{$\operatorname{lag} 12$} & Ist Qu. & $-0,401$ & $-0,293$ & $-0,302$ & $-0,222$ & $.0,210$ \\
\hline & Moan & $-0,238$ & $-0,131$ & $-0,161$ & $.0,056$ & $-0,037$ \\
\hline & Mocian & $.0,249$ & $-0,139$ & $-0,168$ & $-0,067$ & $-0,038$ \\
\hline & 3rdQu. & $-0,088$ & 0,009 & $-0,030$ & 0,094 & 0,129 \\
\hline \multirow[t]{4}{*}{$\log 18$} & IstQu. & $-0,423$ & $-0,346$ & $.0,278$ & $-0,184$ & $-0,249$ \\
\hline & Meen & $-0,264$ & $-0,215$ & $.0,136$ & $-0,026$ & $-0,084$ \\
\hline & Modian & $-0,288$ & $-0,222$ & $-0,136$ & $-0,029$ & $.0,077$ \\
\hline & 3rdQu. & $-0,151$ & $-0,092$ & 0.004 & 0,128 & 0,086 \\
\hline \multirow[t]{4}{*}{$\operatorname{lag} 24$} & IstQu. & $-0,279$ & $-0,100$ & $-0,084$ & $-0,138$ & $-0,179$ \\
\hline & Maen & $-0,136$ & 0,031 & 0,058 & $-0,012$ & $-0,035$ \\
\hline & Modian & $-0,136$ & 0,024 & 0,063 & $.0,019$ & $-0,027$ \\
\hline & 3rdQu. & 0,011 & 0,152 & 0,201 & 0,110 & 0,120 \\
\hline \multirow[t]{4}{*}{ cumul 12} & Ist Qu. & $-2,158$ & $-2,354$ & $-2,278$ & $-2,401$ & $-1,952$ \\
\hline & Moon & $-1,167$ & $-1,485$ & $-1,346$ & $-1,499$ & $-0,959$ \\
\hline & Median & $-1,245$ & $-1,637$ & $-1,501$ & $-1,574$ & $-1,055$ \\
\hline & 3rdQu. & $-0,357$ & $-0,672$ & $-0,614$ & $.0,760$ & $-0,094$ \\
\hline \multirow[t]{4}{*}{ cumul 24} & 1 st Qu. & $-3,862$ & $-3,881$ & $-3,588$ & $-3,312$ & $-2,562$ \\
\hline & Maen & $-2,222$ & $-2,231$ & $-2,136$ & $-1,700$ & $-1,008$ \\
\hline & Median & $-2,703$ & $-2,695$ & $-2,550$ & $-1,995$ & $-1,158$ \\
\hline & 3rd Qu. & $-1,209$ & $-1,172$ & $-1,180$ & -0.624 & $-0,324$ \\
\hline
\end{tabular}

Note: For each lag the first quartile, the mean, the median, and the third quartile are reported 
Table 13. Mean estimated impact of a common monetary policy shock. Several lags. All years

\begin{tabular}{|c|c|c|c|c|c|c|}
\hline & & 1994 & 1895 & 1986 & 1997 & 1998 \\
\hline \multirow[t]{4}{*}{$\log 1$} & IstQu. & $-0,363$ & $.0,337$ & $-0,250$ & $.0,285$ & $.0,270$ \\
\hline & Moan & 0,069 & $-0,058$ & 0,028 & 0,047 & 0,072 \\
\hline & Medien & $-0,088$ & 0,081 & 0,021 & 0,074 & 0,126 \\
\hline & 3nd Qu. & 0,217 & 0,205 & 0,274 & 0,375 & 0,467 \\
\hline \multirow[t]{4}{*}{$\log 6$} & Ist Qu. & $-0,427$ & $.0,359$ & $-0,391$ & $\cdot 0,507$ & $\cdot 0,673$ \\
\hline & Moan & 0,004 & $-0,038$ & $-0,078$ & $-0,252$ & $-0,361$ \\
\hline & Medien & 0,060 & $-0,047$ & $-0,081$ & $-0,257$ & 0,366 \\
\hline & 3nd Qu. & 0,420 & 0,312 & 0,241 & 0,017 & 0.022 \\
\hline \multirow[t]{4}{*}{$\log 9$} & 1st Qu. & $.0,690$ & $.0,890$ & $.0,982$ & $-1,289$ & $-1,395$ \\
\hline & Moan & $-0,340$ & $-0,860$ & $-0,652$ & $-0,959$ & $-0,958$ \\
\hline & Medien & $-0,366$ & 0,099 & $-0,671$ & $-0,922$ & $-0,931$ \\
\hline & 3nd Qu. & $.0,032$ & $-0,219$ & $-0,332$ & $-0,575$ & $-0,550$ \\
\hline \multirow[t]{4}{*}{$\log 12$} & 1 st Qu. & $-0,207$ & $-0,313$ & $\cdot 0,372$ & $-0,300$ & $-0,071$ \\
\hline & Mean & 0,052 & $-0,070$ & 0,130 & $-0,030$ & 0,296 \\
\hline & Median & 0,069 & $-0,069$ & 0,134 & $-0,008$ & 0,211 \\
\hline & 3rdQu. & 0,312 & 0,188 & 0,119 & 0,247 & 0,511 \\
\hline \multirow[t]{4}{*}{$\log 18$} & IstQu. & $-0,718$ & 0,592 & $\cdot 0,481$ & $\cdot 0,567$ & $-0,561$ \\
\hline & Mean & $-0,465$ & $-0,300$ & $-0,154$ & $-0,229$ & $-0,195$ \\
\hline & Medien & $-0,491$ & $-0,346$ & $-0,262$ & $-0,309$ & $-0,297$ \\
\hline & 3nd Qu. & $-0,237$ & $.0,052$ & 0,136 & $-0,003$ & 0,024 \\
\hline \multirow[t]{4}{*}{$\log 20$} & Ist Qu. & $\cdot 0,545$ & $\cdot 0,507$ & $-0,523$ & $\cdot 0,553$ & $.0,517$ \\
\hline & Moan & $-0,286$ & $-0,230$ & $-0,272$ & $-0,293$ & $-0,203$ \\
\hline & Medien & 0,256 & $-0,266$ & $-0,274$ & 0,296 & 0,253 \\
\hline & 3nd Qu. & $.0,014$ & $\cdot 0,077$ & $.0,030$ & $-0,050$ & 0,071 \\
\hline \multirow[t]{4}{*}{ cormul 12} & 1 st Qu. & $-0,689$ & $.0,781$ & $-1,354$ & $-1,631$ & $-1, \pi 71$ \\
\hline & Moan & 0,476 & 0.205 & $-0,252$ & $-0,640$ & $-0,465$ \\
\hline & Medien & 0,465 & 0,283 & $-0,199$ & $-0,491$ & $-0,412$ \\
\hline & 3rd Qu. & 1,633 & 1,249 & 0,874 & 0,330 & 0,773 \\
\hline \multirow[t]{4}{*}{ cumui2s } & Ist Qu. & $-2,071$ & $-2,148$ & $-2,192$ & $-1,878$ & $-1,673$ \\
\hline & Mean & 0,625 & $-0,971$ & $-0,900$ & $-0,701$ & $-0,011$ \\
\hline & Medien & 0,628 & $-0,846$ & $-0,817$ & $-0,099$ & $-0,121$ \\
\hline & 3nd Qu. & 0,808 & 0,361 & 0.543 & 0,562 & 1,680 \\
\hline
\end{tabular}

Note: For each lag the first quartile, the mean, the median, and the third quaitile are reported 
Figure 1. Monetary policy shocks
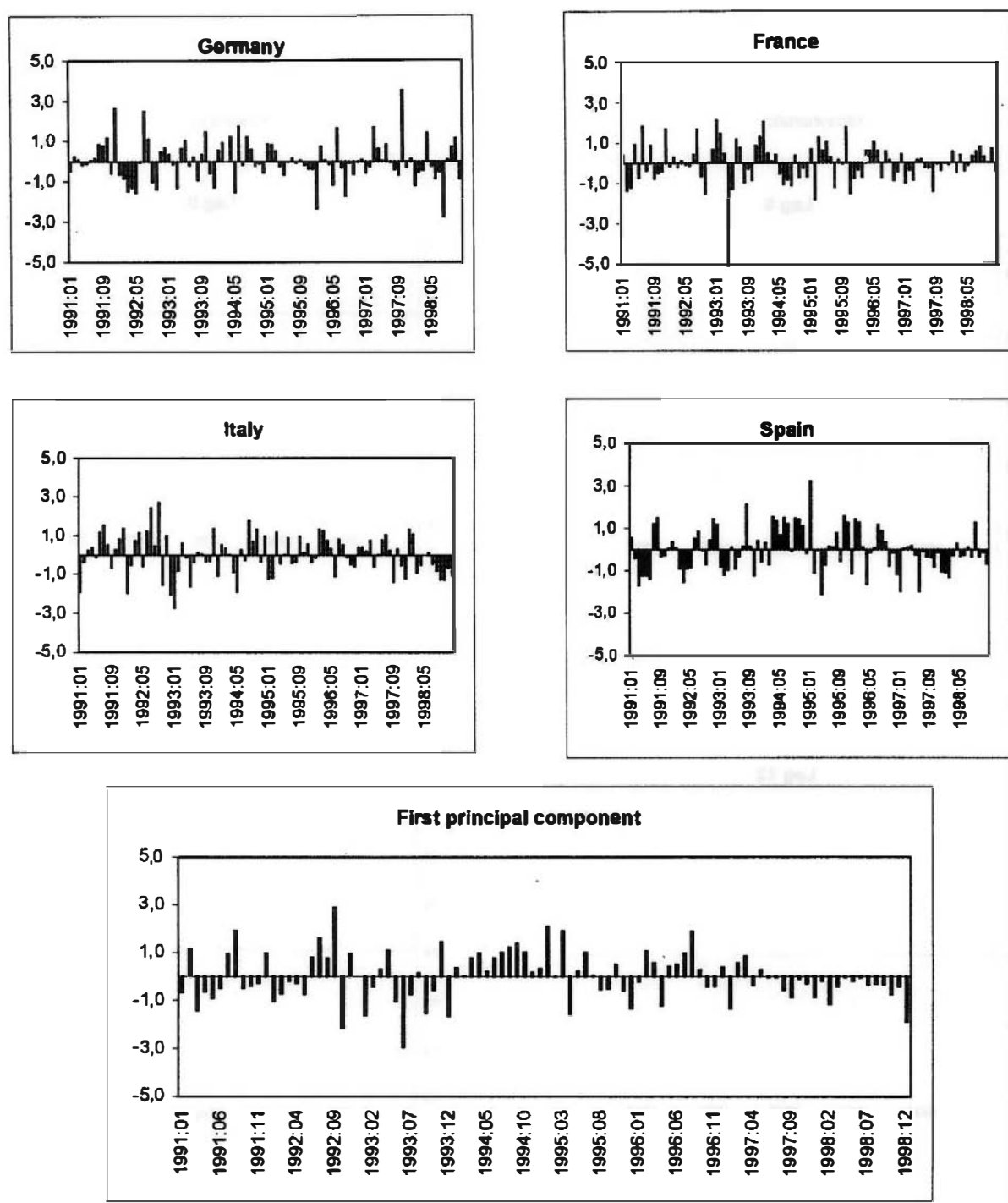
Figure 2. Euro-wide impact of idiosyncratic and common shocks

Idiosyncratic

Lag 9

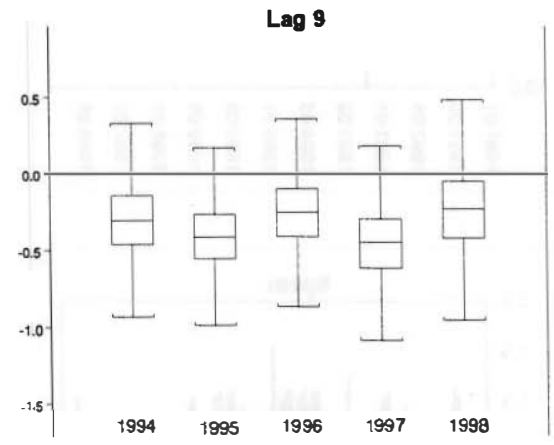

Lag 12

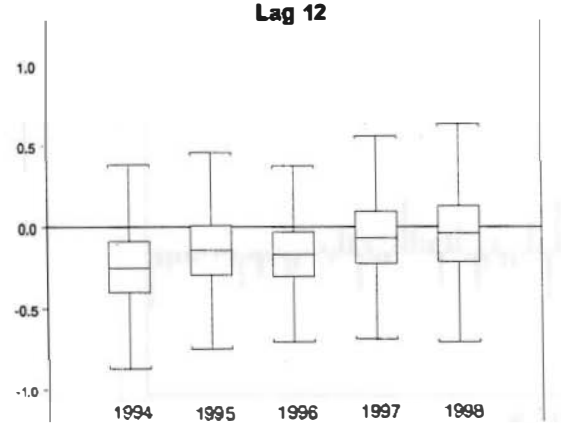

Common

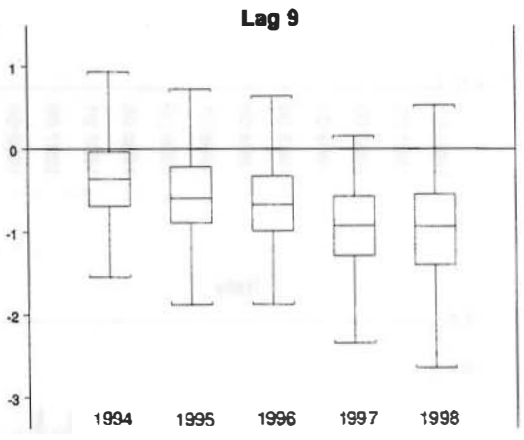

Lag 12

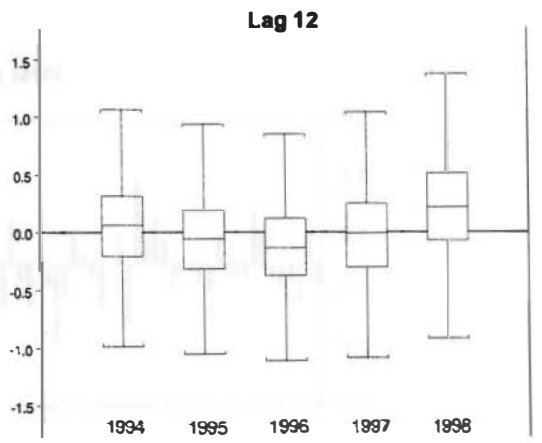


Figure 2. (cont.)
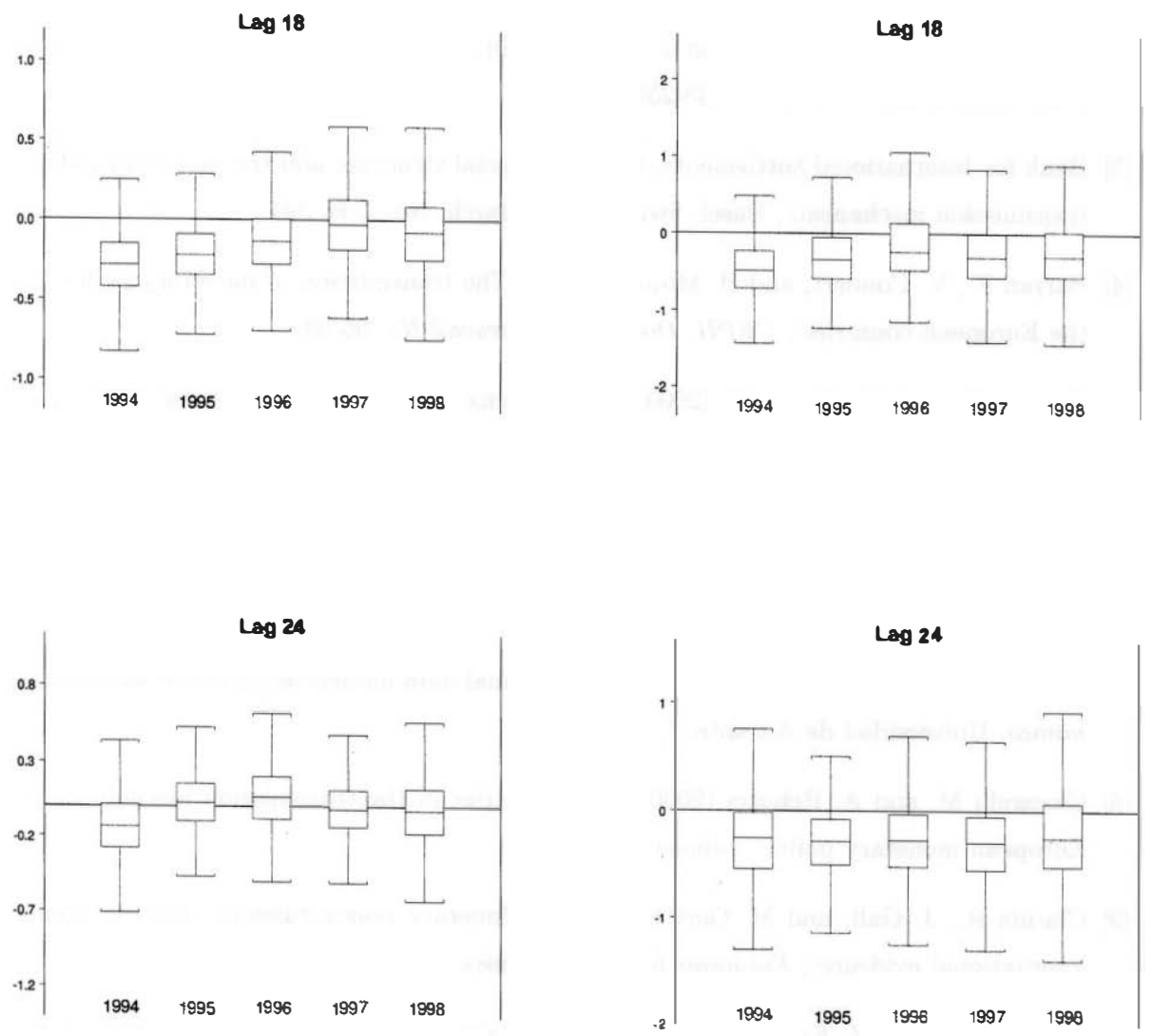


\section{References}

[1] Amisano, G. and C. Giannini (1997), Topics in Structural VAR Econometrics, 2nd ed., Berlin: Springer.

[2] Ballabriga F., M. Sebastián, and J. Vallés (1999), 'European asymmetries', Journal of International Economics, 48, 233-253.

[3] Bank for International Settlements, 1995, 'Financial structure and the monetary policy transmission mechanism', Basel, Switzerland, March, No. C.B. 394.

[4] Barran F., V. Coudert, and B. Mojon (1996), 'The transmission of monetary policy in the European countries', CEPII, Document de travail No. 96-03.

[5] Canova F. and M. Ciccarelli (2000), 'Forecasting and turning point prediction in a Bayesian panel VAR model', mimeo, UPF, Barcelona, Spain.

[6] Chib S. and E. Greenberg (1995), 'Hierarchical analysis of SUR models with extensions to correlated serial errors and time-varying parameter models', Journal of Econometrics, $68,409-431$.

[7] Ciccarelli M. (2000), 'Testing restrictions in normal data models using Gibbs sampling', mimeo, Universidad de Alicante.

[8] Ciccarelli M. and A. Rebucci (2000), 'Asymmetries in the transmission mechanism of European monetary policy', mimeo.

[9] Clarida R., J. Gali, and M. Gertler (1997), 'Monetary policy rules in practice. Some international evidence', European Economic Review, 42, 1033-1067.

[10] Clements B. and Z. Kontolemis (2001), 'Monetary Policy under EMU: Differences in the Transmission Mechanism?', mimeo, International Monetary Fund, Washington DC.

[11] Cecchetti S.G. (1999), 'Legal structure, financial structure and the monetary policy', Federal Reserve Bank of New York, mimeo. 
[12] Dornbusch R., C. Favero, and F. Giavazzi (1998), 'A red letter day', CEPR Discussion Paper No. 1804.

[13] Gelfand A.E. and A.F.M. Smith (1990), Sampling-based approaches to calculating marginal densities, Journal of the American Statistical Association, 85(410):398-409.

[14] Gelfand A.E., S. E. Hills, A. Racine-Poon, and A.F.M. Smith (1990), 'Illustration of Bayesian inference in normal data models using Gibbs sampling', Journal of the American Statistical Association, 85, 972-985.

[15] Geman S. and D. Geman (1984), Stochastic relaxation, Gibbs distributions and the Bayesian restoration of images, IEEE Transactions on Pattern Analysis and Machine Intelligence, 6(6):721-741.

[16] Gerlach S. and F. Smets (1995), 'The monetary transmission mechanism: evidence from the G-7 countries', BIS Discussion Paper.

[17] Giovannetti, G. and R. Marimón (1998), 'An EMU with different transmission mechanisms?', IUE, Working Paper 98/39, Florence.

[18] Guiso L., A.K. Kashyap, F. Panetta, and D. Terlizzese (2000), 'Will a common European monetary policy have asymmetric effects?', Economic Perspectives, Federal Reserve Bank of Chicago.

[19] Hsiao, C., M. H. Pesaran and A. K. Tahmiscioglu (1997), 'Bayes estimation of short run coefficients in dynamic panel data models', mimeo, Cambridge University.

[20] Kim S. (1998), 'Identifying European monetary policy interactions: French and Spanish system with German variables', Bank of Spain, Working Paper No. 9811.

[21] Leamer E. E. (1978), Specification Searches. Ad Hoc Inference with Nonexperimental Data, New York: Wiley.

[22] Litterman, R. (1980), 'Techniques for forecasting with vector autoregressions', University of Minnesota, Ph.D. Thesis. 
[23] Litterman, R. (1986), 'Forecasting with Bayesian vector autoregressions: five years of experience', Journal of Business and Economic Statistics, 4, 25-38.

[24] Monticelli C. and O. Tristani (1999), 'What does the single monetary policy do? A SVAR benchmark for the European Central Bank', ECB Working Paper, No. 2.

[25] Ortega E. and E. Alberola (2000), 'Transmission of shocks and monetary policy in the Euro area. An exercise with NIGEM', Bank of Spain, Working Paper No. 0010.

[26) Pesaran M.H. and R. Smith (1995), 'Estimating long run relationships from dynamic heterogeneous panels', Journal of Econometrics, 68, 79-113.

[27] Peersman G. and F. Smets (1998), 'The Taylor rule: A useful monetary policy guide for the ECB?', paper presented at the conference 'Monetary Policy of the ESCB: Strategic and Implementation Issues', Bocconi University, Milan, Italy.

[28] Ramaswamy R. and T. Sloek (1997), 'The real effects of monetary policy in the European Union: what are the differences?' IMF Working Paper No. 97/160.

[29] Rebucci, A. (2000), 'Estimating vector autoregressions with long heterogeneous panels', mimeo, International Monetary Fund, Washington DC.

[30] Sala, L.(2000), 'Monetary transmission in the Euro area: a factor model approach', mimeo, ULB-ECARES.

[31] Sims, C. and T. Zha (1998), 'Bayesian methods for dynamic multivariate models', International Economic Review, 39, 949-979.

[32] Smets, F. (1997), 'Measuring monetary policy shocks in France, Germany and Italy: the role of the exchange rate', BIS Discussion Paper.

[33] Theil, H. (1971), Principles of Eiconometrics, New York: Wiley.

[34] Zellner, A. (1971), An Introduction to Bayesian Inference in Econometrics, New York: Wiley.

[35] Zha, T. (1999), 'Block recursion and structural vector autoregressions', Journal of Econometrics 90, 291-316. 


\section{WORKING PAPERS (1)}

9927 Ignacio Fuentes and Teresa Sastre: Merkers and acquisitions in the Spanish Banking industry: some empirical evidence.

0001 Georges Siotis: Market power, total factor productivity growth, and structural change. An illustration for Spain, 1983-1996.

0002 Alberto Cabrero: Seasonal adjustment in economic time series: The experience of the Banco de España (with the model-based method)

0003 Luis Gordo and Pablo Hernández de Cos: The financing arrangements for the regional (autonomous) governments for the period 1997-2001. (The Spanish original of this publication has the same number.)

0004 J. Andrés, F. Ballabriga and J. Vallés: Monetary Policy and Exchange Rate Behavior in the Fiscal Theory of the Price Level.

0005 Michael Binder, Cheng Hsiao and M. Hashem Pesaran: Estimation and Inference in Short Panel Vector Autoregressions with Unit Roots and Cointegration.

0006 Enrique Alberola and Luis Molina: Fiscal discipline \& Exchange Rate Regimes. A case for currency Boards?

0007 Soledad Núñez y Miguel Pérez: La rama de servicios en España: un análisis comparado.

0008 Olympia Bover and Nadine Watson: Are There Economies of Scale in the Demand for Money by Firns? Some Panel Data Estimates.

0009 Ángel Estrada, Ignacio Hernando and J. David López-Salido: Measuring the NAIRU in the Spanish Economy.

0010 Eva Ortega and Enrique Alberola: Transmission of shocks and monetary policy in the euro area. An exercise with NIGEM. (The Spanish original of this publication has the same number.)

0011 Regina Kaiser and Agustín Maravall: An Application of TRAMO-SEATS: Changes in Seasonality and Current Trend-Cycle Assessment. The German Retail Trade Turnover Series

0012 Regina Kaiser and Agustin Maravall: Notes on Time Series Analysis, ARIMA Models and Signal Extraction.

0013 Jordi Galí, J. David López-Salido and Javier Vallés: Technology Shocks and Monetary Policy: Assessing the Fed's Performance.

0014 Agustín Maravall and Fernando J. Sánchez: An Application of TRAMO-SEATS: Model Selection and Out-of-sample Performance. The Swiss CPI series.

0015 Olympia Bover, Samuel Bentolila and Manuel Arellano: The Distribution of Earnings in Spain during the 1980s: The Effects of Skill, Unemployment, and Union Power.

0016 Juan Ayuso and Rafael Repullo: A Model of the Open Market Operations of the European Central Bank.

0017 Francisco Alonso, Roberto Blanco, Ana del Rio and Alicia Sanchís: Estimating liquidity premia in the Spanish government securities market.

0018 Santiago Fernández de Lis, Jorge Martinez Pagés and Jesús Saurina: Credit growth, problem loans and credit risk provisioning in Spain.

0019 Pablo Hernández de Cos, Isabel Argimón and José Manuel González-Páramo: Does public ownership affect business performance? Empirical evidence with panel data from the Spanish manufacturing sector. (The Spanish original of this publication has the same number.)

0020 Jordi Galí, Mark Gertler and J. David López-Salido: European inflation dynamics. 
0101 Silvio Rendón: Job Creation under Liquidity Constraints: The Spanish Case.

0102 Ravi Balakrishnan: The interaction of firing costs and on-the-job search: an application of a search theoretic model to the Spanish labour market.

0103 Francisco de Castro, José Manuel González-Páramo and Pablo Hernández de Cos: Evaluating the dynamics of fiscal policy in Spain: patterns of interdependence and consistency of public expenditure and revenues.

0104 Carsten Krabbe Nielsen: Three Exchange Rate Regimes and a Monetary Union: Determinacy, Currency Crises, and Welfare.

0105 Juan Ayuso and Rafael Repullo: Why Did the Banks Overbid? An Empirical Model of the Fixed Rate Tenders of the European Central Bank.

0106 Francisco J. Ruge-Murcia: Inflation targeting under asymmetric preferences.

0107 José Viñals: Monetary policy issues in a low inflation environment.

0108 Agustín Maravall and Ana del Río: Time aggregation and the Hodrick-Prescott filter.

0109 Jordi Galíand J. David López-Salido: A New Phillips Curve for Spain.

0110 Ángel Estrada and David López-Salido: Accounting for Spanish productivity growth using sectoral data: New evidence.

0111 Francisco Alonso, Roberto Blanco and Ana del Río: Estimating inflation expectations using french government inflation-indexed bonds.

0112 Gianluca Caporello, Agustín Maravall and Fernando J. Sánchez: Program TSW. Reference manual.

0113 Soledad Núñez Ramos y Miguel Pérez García-Mirasierra: El grado de concentración en las ramas productivas de la economia española.

0114 Klaus Desmet and Ignacio Ortuño Ortin: Rational underdevelopment.

0115 Matteo Ciccarelli and Alessandro Rebucci: The transmission mechanism of european monetary policy: Is there heterogeneity? Is it changing over time?

(1) Previously published Working Papers are listed in the Banco de España publications catalogue.

Queries should be addressed to: Banco de España

Sección de Publicaciones. Negociado de Distribución y Gestión

Telephone: 913385180

Alcalá, 50.28014 Madrid 